DIW BERLIN

Discussion Papers

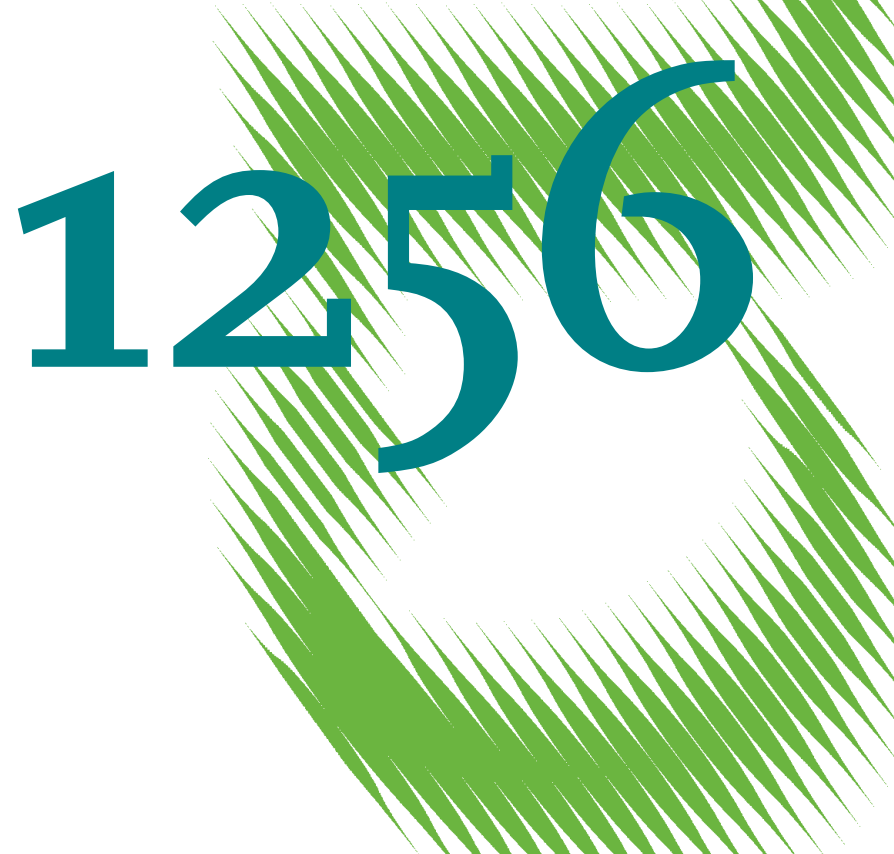

The Treatment Effect of Attending

a High-Quality School and the Influence of Unobservables 
Opinions expressed in this paper are those of the author(s) and do not necessarily reflect views of the institute.

IMPRESSUM

(C) DIW Berlin, 2012

DIW Berlin

German Institute for Economic Research

Mohrenstr. 58

10117 Berlin

Tel. $+49(30) 89789-0$

Fax +49 (30) $89789-200$

http://www.diw.de

ISSN print edition $1433-0210$

ISSN electronic edition 1619-4535

Papers can be downloaded free of charge from the DIW Berlin website:

http://www.diw.de/discussionpapers

Discussion Papers of DIW Berlin are indexed in RePEc and SSRN:

http://ideas.repec.org/s/diw/diwwpp.html

http://www.ssrn.com/link/DIW-Berlin-German-Inst-Econ-Res.html 


\title{
The treatment effect of attending a high-quality school and the influence of unobservables
}

\author{
Ronny Freier \\ DIW Berlin \\ Email: rfreier@diw.de \\ Johanna Storck \\ DIW Berlin \\ Email: jstorck@diw.de
}
Keywords: $\quad$ secondary school choice, school quality
instrumental variable estimation, selection on unobservables

JEL classification: I20, I21 


\begin{abstract}
:
This paper studies the effect of attending a high-quality secondary school on subsequent educational outcomes. The analysis is based on data from the German Socio-Economic Panel Study in which we observe children when they make their secondary school choice (between ages 10-12) and later when they self-report on their intentions with regard to their further educational path (between ages 16-17). To identify the treatment effect, we use a regression-control framework as well as an instrumental variable approach (based on local supply of schools). In a second step, we carefully examine the influence of unobservable characteristics, using the new technique proposed by Altonji, Elder, and Taber (2005b). Our findings suggest that unobservable characteristics are indeed crucial to the validity of the research design. While we find large positive and significant effects of attending a high-quality school, we cannot rule out that the estimates are not in fact driven by selection on unobservables.
\end{abstract}

Acknowledgments: We would like to thank Joseph Altonji, Todd E. Elder, Frank Fossen, Peter Haan, Henrik Jordahl, Daniel Kemptner, Christian Odendahl, Viktor Steiner and Katharina Wrohlich, participants of the DIW Cluster Seminar and the FU Berlin WIPO-Seminar. Comments of colleagues at DIW Berlin and the Stockholm School of Economics are also gratefully acknowledged. The usual disclaimer applies.

Mailing address: Ronny Freier: DIW Berlin, Department of Public Economics, Mohrenstrasse 58, 10117 Berlin (rfreier@diw.de); Johanna Storck (corresponding author): DIW Berlin, Department of Education Policy (jstorck@diw.de) 


\section{Introduction}

Many countries pursue a schooling policy in which children (sometimes at very early age) are segregated into school tracks with very different educational ambitions. As a result, children in such school systems often find themselves sorted into a group of students with high or low average academic merits. Naturally, both economic researchers and policy makers are interested in understanding the effects that this tracking has on the child's future educational career and later labor market outcomes.

In Germany, the case studied here, children are separated into different types of secondary school at the age of 10 . The school types differ with respect to their level of academic ambitions, curriculum and years to receive a degree. Three main types of schools can be distinguished at this stage, following Dustmann, Puhani, and Schönberg (2012) we will simply denote them as high, middle or low quality schools.1 The selection into these different schools is based on a system in which teachers recommend an appropriate school form for the child according to an evaluation of academic merit. However, the system has been shown to implicitly take other factors into account, including for example, the educational ambitions of the parents (Lohmann and Groh-Samberg, 2010).2 Once the decision has been made, the child will mostly remain with that school type for 4-5 years before they have a chance to up- or downgrade between schools. During that time, students at the high-quality school will study among high-achieving peers, they will have better educated and better paid teachers and they will be subject to a more stringent curriculum.

This paper studies the effect of attending a high-quality school between the ages of 10 and 15 on future educational outcomes. For the analysis, we combine individual data on children and their parents from the German Socio-Economic Panel (SOEP) with administrative data on school supply at the regional level. In the SOEP, we track pupils between the age of 10-12 and observe their secondary school choice. We then follow the same children through to the age of 16-17, when they are being surveyed on their self-assessed future educational pathway. In the paper, we will focus on two particular outcomes: (1) the self-reported intention to finish the Abitur (The German university entrance diploma), (2) the intention to seek higher, tertiary, education.

The main challenge in evaluating the causal effect of attending the high-quality secondary school is the inherent endogeneity in school choice. To overcome this problem, researchers have applied methods such as regression control frameworks as well as program evaluation

\footnotetext{
${ }^{1}$ For further details see the section on the institutional setting in Germany, section 3 .

${ }^{2}$ Also the recommendations are not always binding such that parents can challenge the initial recommendation and see to it that their child will be placed in a better school.
} 
techniques such as instrumental variable estimation. Using detailed control variables at the individual and household levels, we also highlight the results of simple regression control estimates. Moreover, we have information on local school supply and we instrument individual school attendance with these regional information. Specifically, we use local supply as an instrument in two different ways: (1) a dummy variable that indicates whether the town has a high-quality school within its borders and (2) a variable for the share of high-quality school positions in all secondary schooling within the county.

Methodologically, we then explicitly test for the influence of unobserved factors both in the OLS framework and in the instrumental variable estimation. Here, we apply the new technique proposed by Altonji et al. (2005b). $!^{3}$ In this method, we draw conclusions on the potential bias from selection on unobservables by carefully examining the selection on the observable characteristics.

Our findings highlight that unobservables may indeed play a crucial role in the evaluation of the treatment effect of interest. While the traditional regression control and instrumental variable techniques signal a large positive and significant effect of attending a high-quality school, the new method by Altonji et al. (2005b) points to the fact that even a modest degree of selection on unobservables (relative to selection on observables) suffices to explain away the entire effect. This finding may be hardly surprising for the case of the regression control framework (even with detailed and relevant controls), however, the influence of unobservables is also potentially large in our instrumental variable design.

With this analysis, the paper contributes to three main strands of literature. First, we add to the literature on school quality. A number of papers for the U.S. have found large and consistent effects of attending (private) catholic schools, which are often substantially better than public schools (see Evans and Schwab (1995), Neal (1997), Altonji et al. (2005b)). For Germany, Dustmann et al. (2012) provide an analysis similar to ours in which they use a different instrument (school entry age as a cut-off rule). They report no significant long-run gains from attending a high-quality school, a result that is consistent with our findings.

Secondly, our paper also speaks to the literature on peer effects. In evaluating the effect of attending a high-quality school, we implicitly draw the attention to the potential mechanism of peer effects. Here, we can compare our results to a large body of research that addresses the effects of children's peers (f.ex. Ammermueller and Pischke (2009), Bifulco, Fletcher, and Ross (2011), Schneeweis and Winter-Ebmer (2007)).

\footnotetext{
${ }^{3}$ Note that the initial paper only develops the method for the regression control framework. In an additional paper, the same authors also adjust their new technique to be validate instrumental variable approaches Altonji, Elder, and Taber (2005a).
} 
Knowledge about the magnitude of peer effects on educational achievement is highly relevant, especially in a system of separated schools. Depending on the school track, the composition of peers differs widely. Hence, the benefit of attending a high-quality school could be twofold. Students benefit not just from higher qualified teachers and a more stringent curriculum but also from more ambitious peers. Especially for students who are at the margin of attending a high-quality school, a better peer group can have a significant impact on educational achievements.

Finally, our paper provides valuable insights for the rich literature that is concern with using proximity to educational institutions. Here, researchers have both been interested to study the direct effect of distance to institutions of education (Do (2004), Frenette (2006), Spiess and Wrohlich (2010), Denzler and Wolter (2011)) as well as the possibilities to use those variables as instruments (Card (1995)). Our findings confirm the recent critic on the use of those variables (Altonji et al. (2005a) ) and the potential problems due to the influence of unobservable characteristics. A more detailed review of the literature will follow in the next section.

The remaining part of the paper is structured as follows. After this introduction and the survey of the relevant literature, section 3 highlights the main institutional features of the German secondary school system. Then, section 4 discusses the empirical methodology, before we introduce our data and give descriptive statistics in section 5. Section 6 provides our empirical findings. Section 7 concludes the analysis.

\section{Literature}

This section reviews the related literature. As mentioned above, the analysis aims to contribute to three main strands of literature. Below, we illustrate how the paper relates to the literature of school quality, to studies of the effects of peers and the system of school tracking, as well as to the body of work concerned with proximity to educational institutions.

For the U.S., a number of studies are concerned with the effects of attending (private) catholic schools. Compared to the public school systems, catholic schools often provide better quality education. Naturally, researchers are interested in analyzing the quantitative effect that this quality difference has on educational outcomes and wages. Evans and Schwab (1995) estimate the effect on the probability of finishing high school as well as starting college. To account for the endogeneity of attending a catholic school they apply an instrumental variable approach based on catholic religion of the family and having a catholic 
school close by. They find an effect of attending a catholic school on subsequent educational outcomes of about 13 percentage points on high school graduation and college attendance rates. Neal (1997) uses a very similar instrumental variable approach but additionally evaluates the effects of attending a catholic school on college graduation rates and wages. He finds that the positive effect of catholic school attendance is mainly driven by the effect it has on urban minorities.

The papers by Altonji et al. (2005a b) take a second look at the effect of school quality related to catholic schools. In Altonji et al. (2005b) the authors develop a technique (AET technique in the following) based on the idea that the amount of selection on the observed explanatory variables in a model provides a guide to the amount of selection on observables (see section 4.3). Applying the new method they support the earlier findings that catholic school attendance has a significant effect of subsequent educational outcomes. In Altonji et al. (2005a), the authors apply the new method also to check on the validity of the instruments used by Evans and Schwab (1995) and Neal (1997). They find, that these instrumental variable approaches are prone to significant bias from unobservables. Both papers directly relate to our study also in terms of the methodology.

For Germany, Dustmann et al. (2012) provide an analysis similar to ours in which they evaluate the effect of attending a high-quality secondary school. They use a different instrument in which they make use of the school entry cut-off rule. Based on this rule, children will enter elementary school at different ages (up to 11 months difference) which can be shown to significantly affect the probability of attending a high-quality secondary school. They report no significant gains from attending a high-quality school. Without controlling for selection into the types of school, they find that students attending a highquality school at age 14 are 50 percent more likely to obtain the Abitur than students attending a middle-quality school at age 14. Further, the first group earns at least 10 percent higher wages. However, when applying an IV-strategy to account for selection into the school types, attending a more academic secondary school has little effect on school type completed, education completed and wages.

Our paper also speaks to the literature on peer effects and the effect of tracking. The starting point for the explanation of peer effects is the assumption that children not only learn from their teachers but from class-/ and schoolmates, too. The peer group is an important source of motivation and aspiration (Schneeweis and Winter-Ebmer (2007)). Most studies on peer effects find significant effects of peer-group composition on educational achievements (see Lavy, Silva, and Weinhardt (2012), Vardardottir (2012), Ammermueller and Pischke (2009), Gould, Lavy, and Paserman (2009), Schneeweis and Winter-Ebmer (2007), Hoxby (2000)). 
In our setting, thus, students are exposed to different peers because they are tracked into different school types. The results of studies that estimate the effect of tracking on educational outcomes are mixed. Brunello and Checchi (2007) find positive effects of the tracking system on a students performance using constraints on educational participation, such as financial constraints or family reasons as an instrumental variable. Hanushek and Wössmann (2006) match international primary school tests to secondary school tests and compare differences in test scores across countries. They find that early tracking has no clear impact on average achievers. Our study contributes to this stream of literature by asking the question if students who are at the margin getting tracked to a high-quality school benefit from the more academic environment.

Finally, our study is related to the literature on proximity to educational institutions. In a seminal paper, Card (1995) uses the distance to the next college to instrument the years of schooling in a Mincer-type wage regression. Since then, many studies have taken a similar approach to instrument schooling variables (Denzler and Wolter (2011), Frenette (2009), Frenette (2006), Evans and Schwab (1995), Neal (1997)). As mentioned above, we should point out that the use of proximity as an instrument has recently been criticized (see Altonji et al. (2005a)).

Moreover, researchers are also interested in analyzing the direct effect of proximity on attending a certain educational institution. For example, Spiess and Wrohlich (2010) estimate the effect the proximity to a college and find that a 10 kilometer decrease in the distance to a university, increases the probability to enrol in higher education by 2-3 percentage points. Similarly, Falch, Lujala, and Strøm (2011) and Virtanen and Väänänen (2010) ask for the effect of distance on the probability of attending a college or a school with specific track in Norway and Finland.

\section{Institutional setting}

This section introduces the details of the German educational system with specific regard to the tracking system for secondary education. We highlight the types of secondary schools that parents and children can choose from, as well as what differentiates a high-quality school from other schools, and how school choice is made.

In Germany, pupils generally finish elementary school at the age of 10, after 4 years of schooling. A $^{-1}$ After elementary school, children separate into different types of schools. The

\footnotetext{
${ }^{4}$ In some federal states pupils finish elementary school first after 6 years (at the age of 12). These states are: Brandenburg, Berlin, Mecklenburg-Western Pomerania. Between 1981 and 2004 Lower Saxony also delayed tracking decisions until grade 6 .
} 
system mainly distinguishes three types of schools. The upper secondary school (Gymnasium) is what we call a high-quality school. Throughout our observation period, about 33 percent of all children attended this type of secondary school. The remaining pupils attend a school of lower quality. The most important school types here are the general school (Hauptschule) as well as the intermediate school (Realschule) ${ }^{5}$

Usually students remain at their secondary school until grade 10.6 Pupils attending a Hauptschule or a Realschule will earn a school degree that enables them to proceed into the vocational training system. Although students attending a Gymnasium may also opt out after 10 years of schooling, the expected educational path continues for an additional two to three years ${ }^{7}$ and finish school earning the Abitur. The Abitur is required for those seeking university education. ${ }^{8}$

It is of particular importance for our study to point out that students from lower-quality schools are also able to pursue the Abitur. To do this, they will eventually have to transfer to a Gymnasium or comprehensive school that offers the Abitur. While pupils are in principle free to transfer at any time, only a very small number of pupils decide to transfer prior to starting grade 10. However, after completing the lower-quality or middle-quality school after 9 or 10 years, about 20 percent of students transfer, upgrading their school degree (see Dustmann et al. (2012)).

Since the further educational path for each secondary school type differ, the schools vary with respect to the curriculum, the academic ability of the peers, as well as the quality and pay of teachers. Dustmann et al. (2012) describe the quality differences of the schools in detail. The number of hours taught per week, for example, is 36 at a high-quality school but only 32 at the other school types. Consequently, the subjects and learning goals differ by school. Lower track schools put a special emphasis in the ninth grade on applications preparing for the entrance into the labor market (writing CVs, preparation

\footnotetext{
${ }^{5}$ Note that about 10 percent of students attend a school type outside the three-track system. In addition to the three main tracks, most states offer comprehensive schools. At this type of school, pupils with different achievement levels learn together for a longer period. The various forms of schooling are all organized together and all types of secondary school degrees can be obtained.

${ }^{6}$ For those attending a Hauptschule, education is complete after grade 9, but, under German law, children cannot leave school before turning 16 .

${ }^{7}$ During our observation period, this track typically required an additional 3 years beyond what was expected for those attending a Hauptschule or a Realschule. The exceptions are in the federal states of Saxony and Thuringia, where students took only two additional years to earn their degree. In the years after our observation period the time to earn a Gymnasium degree has been shortened to 8 years, for a total of 12 years of education, in most federal states.

${ }^{8}$ Note that students can also obtain a (Fachabitur) at specific schools, which will then enable them to apply for university education as well (often at universities of applied sciences (Fachhochschulen)).
} 
for job interviews), while during the same year, Gymnasiums pay special attention to the analysis and interpretation of various types of texts.

Given that the school types differ immensely, the question of how parents and children select school tracks is important. The school decision is based partly on elementary school grades, teacher recommendations, and parental will. There is no standardized rule or test to determine which type of secondary school a child can attend. In most federal states teachers give the student a recommendation for one of the three school types at the end of elementary school. Parents can then decide if they accept the recommendation or not.9

\section{Empirical model and methodology}

\subsection{Identification problem and regression-control framework}

The focus of this paper is to estimate the relationship between attending a high-quality school and subsequent education outcomes. Denote the outcome with $Y_{i}$ for individual $i$. In this study, we mainly use two binary indicator variables as outcomes. We have information whether a youngster (at the age 16/17) plans to finish the Abitur and whether she intends to continue with post-secondary, tertiary education.

Further denote the treatment variable with $D_{i}$. This variable indicates whether a child attended a high-quality school between the age of $10-15.10$

Consider the following simple OLS model:

$$
\begin{gathered}
Y_{i}=\beta_{0}+\beta_{1} D_{i}+X_{i} \beta+\epsilon_{i} \\
D_{i}=\gamma_{0}+X_{i} \gamma+\vartheta_{i}
\end{gathered}
$$

Eq. 1 represents the outcome equation in which $\beta_{1}$ estimates the effect of treatment on the education attainment. An additional set of controls is captured in $X_{i}$. Eq. 2 describes the selection process into treatment.

In the OLS framework, the parameter $\beta_{1}$ can only be consistently estimated under the restrictive conditional independence assumption (conditional on the observables). This implies that $E[D \cdot \epsilon]=0$. Alternatively, the assumption can be illustrated to mean that $\rho=0$ in the joint distribution of the errors:

\footnotetext{
${ }^{9}$ In the states of Bavaria, Baden-Württenberg and Thuringia the teacher recommendation based on grades was compulsory for the students during our observation period.

${ }^{10}$ Note that in some states the school decision is made at the age of 12 instead of 10.
} 


$$
\left[\begin{array}{l}
\epsilon \\
\vartheta
\end{array}\right] \sim \mathcal{N}\left(\left[\begin{array}{l}
0 \\
0
\end{array}\right],\left[\begin{array}{cc}
\sigma_{\epsilon} & \rho \\
\rho & \sigma_{\vartheta}
\end{array}\right]\right)
$$

Estimating only the OLS model in eq. 1 the coefficient on $D$ would have a causal interpretation if the conditional independence assumption strictly holds. While we are in a position to control for a detailed set of variables both on the level of the family and the child (see section 5), we are concerned that our application of the regression control framework suffers from omitted variable bias.

Specifically, we consider it likely that omitted variables (in $\vartheta_{i}$ ) that present a positive shock in the selection equation are also positively associated in the outcome equation (hence, in $\left.\epsilon_{i}\right)$. Our main concern is, thus, a upward bias of the effect of high-quality school attendance on subsequent school outcomes. As an example, the ambitions of parents concerning their child's education cannot be observed, but, might positively affect the selection into a highquality school as well as later school outcomes.

We pursue two strategies to tackle this identification issue. Firstly, we apply an instrumental variable approach in which we instrument the decision to attend a high-quality school with the local supply of these schools. Secondly, we use the new method of Altonji et al. (2005b) and Altonji et al. (2005a) to test the sensitivity of our estimates to omitted variable bias (see section 4.3) ${ }^{11}$

\subsection{Instrumental variable estimation}

To overcome the omitted variable bias issue in the identification of the treatment effect, we first consider an instrumental variable estimation. Consider a similar system of equation as in eq. 1 and eq. 2, except that we now also include an instrument $Z$ in the selection equation:

$$
\begin{gathered}
Y_{i}=\beta_{0}+\beta_{1} D_{i}+X_{i} \beta+\epsilon_{i} \\
D_{i}=\gamma_{0}+X_{i} \gamma+Z_{i} \delta+\vartheta_{i}
\end{gathered}
$$

For any variable to be a candidate for $Z$ (the instrument), two conditions must be fulfilled. Firstly, the instrument variable must be a strong predictor of treatment in eq. $5, E[D \cdot Z] \neq$ 0. Given our treatment, we are, thus, looking for a variable that significantly shifts the

\footnotetext{
${ }^{11}$ Note that the initial application of the Altonji et al. (2005b) method is very similar to our research question. They evaluate the causal effect of attending a catholic high-school on graduation rates and university attendance. Thus, the method is, while generally applicable, specifically useful in our context.
} 
probability of attending a high-quality secondary school. The second condition is that the variable can be excluded from the outcome equation $4, E\left[\epsilon_{i} \cdot Z\right]=0$.

In our application, we follow a large literature that suggests to use local school supply as an instrument for attending a high-quality school. Specifically, we have two measures for the local availability of an upper secondary high school. First, we coded a dummy variable that indicates whether a high-quality school is situated directly in the municipality where the child lives at the time the school decision is made (see further description in section 5). Secondly, we can use the share of children in a county that is offered a spot in a high-quality school as an instrument for the individual uptake.

The identifying assumption for those instruments to be valid are the following. Firstly, the instruments must be a relevant factor in determining the decision to attend a high-quality school. Here the argument is that transportation costs will have an effect. Parents (and teachers who make the recommendations) tend to favor local schooling and children in towns with a local high-quality school are more likely to attend those institutions. The relevance of our instruments can be tested in the first stage of the 2SLS estimation.

The second assumption is that the instruments are exogenous to unobservable characteristics in the outcome equation. In our case, we would be particularly concerned if parents strategically locate with regard to the supply of such high-quality schools. For the US, we know that location decisions are strongly affected by the local quality of the school (see Black (1999), Bayer, Ferreira, and McMillan (2007)). However, in the context of Germany, we are, ex ante, less worried that choice of location is endogenous. Other than in the US, school finances and school quality are not depended on housing values. Thus, the wealthiness of the area that a family lives in does not determine the availability of a high-quality school.

In general, the independence assumption for the IV is not directly testable. However, similar to the case of OLS, we can use the method by Altonji et al. (2005b a) to study the sensitivity of the IV estimates to selection on unobservables. Relying on the assumption that selection on unobservables is equal to selection on observables, we can evaluate the validity of the IV strategy.

\subsection{Sensitivity of the OLS effect, bias estimation and IV validity}

As argued above, the estimate of the OLS estimation cannot be given a causal interpretation due to potential omitted variable bias. Similarly, IV estimates could be biased if the instrument is likely to pick up the effect of unobservables. Altonji et al. (2005b) developed 
a new method to assess the magnitude of this bias. In the following, we shortly introduce their method (building on their exposition) for the case of OLS.

Altonji et al. (2005b) start from the sensitivity test that was initially proposed by Rosenbaum (1995). Rosenbaum suggests taking equations eq. 1 and 2 above, and modeling the parameter $\rho$ explicitly. While the OLS would set $\rho=0$ by assumption, we could vary $\rho$ in the band between zero and one. Thereby, we would give structure to the covariance pattern between unobservables in the selection and the outcome equation. In varying $\rho$, we can assess the sensitivity of the outcome coefficient of interest with increasing influence of unobservables.

While this sensitivity analysis could be of interest per se, it remains unclear which value of $\rho$ is appropriate. Altonji et al. (2005b) derive a particular value for $\rho$ under an assumption that they denote equality of selection on unobservables and observables. The main idea of their approach is to ask the following question: Given that the independence of unobservables assumption in OLS (or likewise in IV) is likely to be violated, how large would the bias from selection on unobservables be, if that selection is in the same order as the selection on observables.

In their paper, Altonji et al. (2005b) provide an argument why it is reasonable to view the case of equality of selection on unobservables and observables as a natural upper bound of the bias that is due to selection. In their derivation of the approach, they essentially assume that the set of observables is randomly picked from the full set of variables and that, as a result, the variables that are unobserved explain just as much of the selection as the observed measures. In reality, however, we would expect that survey makers as well as researchers pick observable characteristics that are best suited for the analysis at hand. So, while it will hardly ever be the case that we can assume to have captured all relevant information (independence of unobservables), it is more reasonable to argue that we have managed to include observables in the analysis that explain at least as much as unobservables.

The equality of selection on unobservables and observables assumption implies that the following condition holds:

$$
\rho_{A E T}=\frac{\operatorname{Cov}(\epsilon, D)}{\operatorname{Var}(\epsilon)}=\frac{\operatorname{Cov}(X \beta, D)}{\operatorname{Var}(X \beta)}
$$

To the right of this equation is the relationship between treatment and the index of observables (normalized by the size of the variance in that index). That relationship is equated 
to be the same as the relationship between treatment and the unobservable part that determines outcome. This assumption makes it possible to obtain an estimate for the only fundamentally unobservable part $\operatorname{Cov}(\epsilon, D)$ (all three other parts can be estimated).

Now, the fact that we can assess the size of $\operatorname{Cov}(\epsilon, D)$ (under equality of selection) can directly be used to estimate the bias in the OLS. Denote $\tilde{D}$, where the tilde indicates that this variable is the residual of a regression of $D$ on all $X$. For OLS, we know:

$$
\operatorname{plim} \hat{\beta}_{1 O L S}=\beta_{1}+\frac{\operatorname{Cov}(\epsilon, \tilde{D})}{\operatorname{Var}(\tilde{D})}
$$

Now, note that $\operatorname{Cov}(\epsilon, \tilde{D})=\operatorname{Cov}(\epsilon, D)$ as $\epsilon$ and $X$ are orthogonal. Thus, we know the expression of the bias in the OLS and we can substitute in from equation 6 .

$$
\frac{\operatorname{Cov}(\epsilon, D)}{\operatorname{Var}(\tilde{D})}=\frac{\operatorname{Cov}(X \beta, D)}{\operatorname{Var}(X \beta)} \frac{\operatorname{Var}(\epsilon)}{\operatorname{Var}(\tilde{D})}
$$

We can estimate this expression with the following procedure. We first estimate a OLS model of the outcome on all $\mathrm{X}$ (excluding the treatment). From this regression, we get the measure of $\operatorname{Var}(\epsilon)$, which is the variance in the outcome that cannot be explained by our observed control variables. Also, this regression gives us the predicted values, $X \hat{\beta}$. In the next step, we use this predicted index of observables and regress it on our treatment variable, $D$. The coefficient on the predicted index in that regression gives us the term, $\frac{\operatorname{Cov}(X \beta, D)}{\operatorname{Var}(X \beta)}$. To compute the implied bias, we finally need an estimate of the term, $\operatorname{Var}(\tilde{D})$. For that, we regress treatment on all $\mathrm{X}$ and obtain the variance of the residual. Based on those three components, we can now calculate what the implied bias in our OLS estimation would be under the assumption of equality of selection on unobservables and observables.

Altonji et al. (2005b) also suggest computing the ratio of the main OLS treatment effect divided by the implied bias. This ratio, then, measures how strong the selection on unobservables would have to be (relative to selection on observables) to explain the entire OLS treatment effect. If, e.g., the ratio is 2 , selection on unobservables would need to be 2 times stronger as selection on observables.

A similar procedure can also be used to assess the IV validity. The IV assumption is $E\left[\epsilon_{i}\right.$. $Z]=0$, which specifies that the instrumental variable does not correlate with unobserved factors in the outcome equation. In Altonji et al. (2005a), the authors adjust the above procedure to test this IV assumption. The equality of selection on unobservables and observables assumption then yields: 


$$
\frac{\operatorname{Cov}(\epsilon, Z)}{\operatorname{Var}(\epsilon)}=\frac{\operatorname{Cov}(X \beta, Z)}{\operatorname{Var}(X \beta)}
$$

Again, this condition can be used to assess the impact of correlation of the instrument with unobservables under the condition that this relationship is similar to the correlation of the instrument with observable characteristics. Similar to above, this information can then be used to estimate the implied bias in the IV estimation by using the following bias formula:

$$
\operatorname{plim} \hat{\beta}_{1 I V}=\beta_{1}+\frac{\operatorname{Cov}(\epsilon, \tilde{Z})}{\lambda \operatorname{Var}(\tilde{Z})}
$$

where $\lambda$ is the first stage estimate in the 2SLS procedure.

\section{Data and descriptive statistics}

In this paper, we mainly rely on data from the German Socio-Economic Panel (SOEP). The SOEP is a yearly representative panel survey that gathers detailed information on the socioeconomic background of currently more than 21,000 persons living in approximately 12,000 households across Germany. The survey started in 1984 and the most recent available wave is from 2010 .

For the analysis, we sample young pupils aged 16-17 from the SOEP households. At this age, the SOEP provides a specific youth questionnaire ${ }^{12}$ in which information on past schooling, the pupil's attitudes towards school and further education as well as occupational plans are collected. For all individuals that answered this survey, we then try to track them back in time to the point at which they made the relevant schooling decision (the transfer from elementary school to secondary school) at the age between 10 and $122^{13}$ Our final sample contains 2,679 young adults.

Our sampling period is 1992 through 2010. The specific youth survey was first introduced in 1999. Thus, we observe the first respondents of this survey to have made their schooling choices in 1992. We then use all available waves of the SOEP until 2010. Table A1 shows

\footnotetext{
${ }^{12}$ At the age of $16-17$ it is the first time in the SOEP that the young adults are interviewed personally. Before that interview all information on these young individuals comes only from the household surveys.

${ }^{13}$ The ages 10-12 is when those schooling decisions are typically made. In our data, we can also track the majority of children in the SOEP households back to that time. However, for a smaller group of children, we can only track them back to when they were 13 or even 14 . We still use the information from those children in the analysis, with the additional assumption that their initial schooling choice at the age of 10-12 was identical to the one we observe when they are 13-14. We believe that this assumption is not critical as transfers from one school type to another is infrequent at these ages.
} 
how our sample is composed over time and by the age at which we observe the initial schooling decision.

We consider two outcome variables, both of which are measured in the youth questionnaire at age 16-17. Our first measure of interest is the respondent's self-assessed intention to finish the Abitur which serves as a university entrance degree in the German education system (see above). We code a dummy variable if students plan to finish this degree in the future ${ }^{14}$ The second educational measure that we use is a similar dummy on the intention to continue education at the university level. Here, the young adults are asked how they assess the likelihood that they will continue schooling at the university level. ${ }^{15}$

Our treatment variable is whether a child (age 10-12) attends a high-quality school (Gymnasium). We obtain this information from the household surveys (answered by the parents) at the relevant age. Overall, only 33 percent of the children obtained a spot at this highest school track. In total, there are about 2800 such schools in Germany, a number that has been decreasing slightly over our sampling period (see figure B1). ${ }^{16}$

In table 1 we highlight the descriptive relationship between attending a high-quality school (treatment) and the subjective educational chances (outcomes). On average, just over 50 percent of all young adults answer positively to the question whether they intend to finish the Abitur. Separated by the specific school track, the difference in this outcome is enormous (89 percent for children in the high-quality schools versus just about 33 in the remaining school types). The picture is similar for the subjective probability to continue a university education. For a significantly smaller sample, we can also assess who indeed finished the Abitur. We find a very similar pattern there 17

The advantage of using the SOEP data is that we can include a rich set of control variables in the analysis. We have information both on the level of the young adult as well as on

\footnotetext{
${ }^{14}$ The questions from which we code this variable are as follows: First, students are asked whether they intend to finish any educational degree in the future. If that question is answered yes, they have to indicate the exact educational degree they plan to obtain. We code the dummy variable as one, if they answer yes to the first question and state that they hope to obtain the Abitur.

${ }^{15}$ Naturally, we would like to use actual educational attainment at the end of the children's school period. Unfortunately, the SOEP allows us to observe only 1200 kids from age 10, when they make their school choice, through the age of 21 , by when they should have finished their school secondary education. This data base proofs too little to estimate the effect of high-quality school attendance on secondary education outcome. To that end, we cannot compare our results to the findings in Dustmann et al. (2012). As new waves are added to the SOEP, such an analysis will become feasible.

${ }^{16}$ The slight drop in figure B1 in the appendix is entirely driven by the demographic development in Germany's former eastern parts. Here, the post reunification drop in the number of children required a significant number of school closures. That drop, however, is partially off set by a modest increase in the number of schools in the former western parts.

${ }^{17}$ The coefficient of correlation between the intention to finish the Abitur and actually earning the degree is 0.69 .
} 
Table 1: Descriptives: educational outcomes by school type attended

\begin{tabular}{lcccc}
\hline \hline & \multicolumn{2}{c}{ Intention to } & & Actual \\
\cline { 2 - 3 } & finish the Abitur & start college & & finished the Abitur \\
\hline Full sample & 51.51 & 40.09 & & 40.43 \\
& & & \\
By school attendance: & & & \\
High-quality school & 89.01 & 71.30 & \\
No high-quality school & 32.79 & 24.51 & & 23.98 \\
\hline
\end{tabular}

Notes: The table illustrates the descriptive relationship between our treatment variable and the outcomes in our analysis. We show the share of young adults that answer our outcome variables positively in the entire sample as well as by the attendance status in a high-quality school.

Source: Own calculations based on SOEP data.

the level of the household that they belong to. For the individual, we know the gender, the number of siblings as well as the initial recommendation for secondary school by the teachers. The last variable is an especially important determinant of school choice and can be used as a proxy for child ability. On the household level, we control for the parents' nationality, both parents' educational attainment, household income as well as information on how much parents cared about school related issues. In table A2, we present descriptive statistics for all control variables by treatment status. Additional to those individual or household level controls, we include state (and sometimes county level) fixed effects as well as fixed effects for cohorts.

To apply our proposed IV strategies, we combine the individual level information on school attendance, school outcomes and other personal characteristics with data on local school supply across Germany. Using the regional information in the SOEP, we can link the local supply of schools within a municipality or county to the individual child's precise location at the age of the school decision. Data on the local school supply have been collected from different databases of the statistical offices of the states 18

We use two different variables as instruments in our analysis. The first is an indicator variable that takes the value one if the municipality that a child of relevant age lives in has a high-quality school within its borders. Overall, there are 14,445 municipalities (as of 1997) in Germany. About 20 percent of those towns have a high-quality school available locally. Figure B2 illustrates how high-quality schools are divided by the distribution of population size. While it is generally true that larger towns have a much greater probability to have a

\footnotetext{
${ }^{18}$ Data on county level education measures are available from the database called Statistik regional available from state statistical offices. Information on municipal level schools was more difficult to obtain. Here, we collected current and past lists of all Gymnasiums from each state that included the actual school address. Based on this information, we manually coded the schools into the municipalities.
} 
Table 2: High-quality school take up: by IV

\begin{tabular}{|c|c|c|c|c|c|}
\hline & \multicolumn{3}{|c|}{ Parents w/ high-quality education } & \multicolumn{2}{|c|}{ Parents socio-economic status } \\
\hline & None & One & Both & Low & High \\
\hline Municipality & & & & & \\
\hline w/o high-quality school & 0.19 & 0.41 & 0.63 & 0.16 & 0.37 \\
\hline w high-quality school & 0.26 & 0.57 & 0.76 & 0.25 & 0.52 \\
\hline \multicolumn{6}{|l|}{ County } \\
\hline low high-quality school supply & 0.19 & 0.43 & 0.74 & 0.15 & 0.38 \\
\hline medium high-quality school supply & 0.23 & 0.49 & 0.61 & 0.21 & 0.45 \\
\hline high high-quality school supply & 0.28 & 0.57 & 0.82 & 0.27 & 0.55 \\
\hline
\end{tabular}

Source: Own calculations based on SOEP data.

Notes: Low socio-economic status: isei score below 43 (out of 90).

locally available high-quality school, we observe considerable variation in the sizes of towns. In figure B3, we also highlight the geographical dispersion (for the state of Bavaria). The graph indicates that for children in municipalities without a high-quality school travel time might indeed be substantial. To address population differences, we include the number of inhabitants of the town as a control in the regression.

In table A3, we show how the descriptive statistics of our control variables vary with this first instrument. We observe about $2 / 3$ of all children in municipalities with a locally available high-quality school (a fact that is very much driven by the larger towns). Control variables between the two groups vary only slightly. Children with a positive IV have slightly more educated parents and their parents are more often foreign born. Also the recommendation for secondary school is more often for a high-quality school. Differences in the descriptive statistics of our control variables by the instrument are notably smaller than the differences by treatment status (see table A2).

Our second candidate variable for an IV is the share of pupils in grade 7 (in all pupils in grade 7) that are attending a high-quality school within a county. In figure B4, we show a map of all German counties (436 in 1997) and in which quartile of the distribution the county falls. The dispersion of locally available high-quality school positions is very large. In the data, we indeed have counties in which no spots for high-quality schools are directly available, while other counties can offer as much as 60 percent of their children a position at a high-quality school. The graph also illustrates that there is considerable variation between states, which formally carry the responsibility for school policy.

Does local availability actually determine whether children attend a high-quality school? 
Figure 1: Probability of high-quality school take up by local school supply

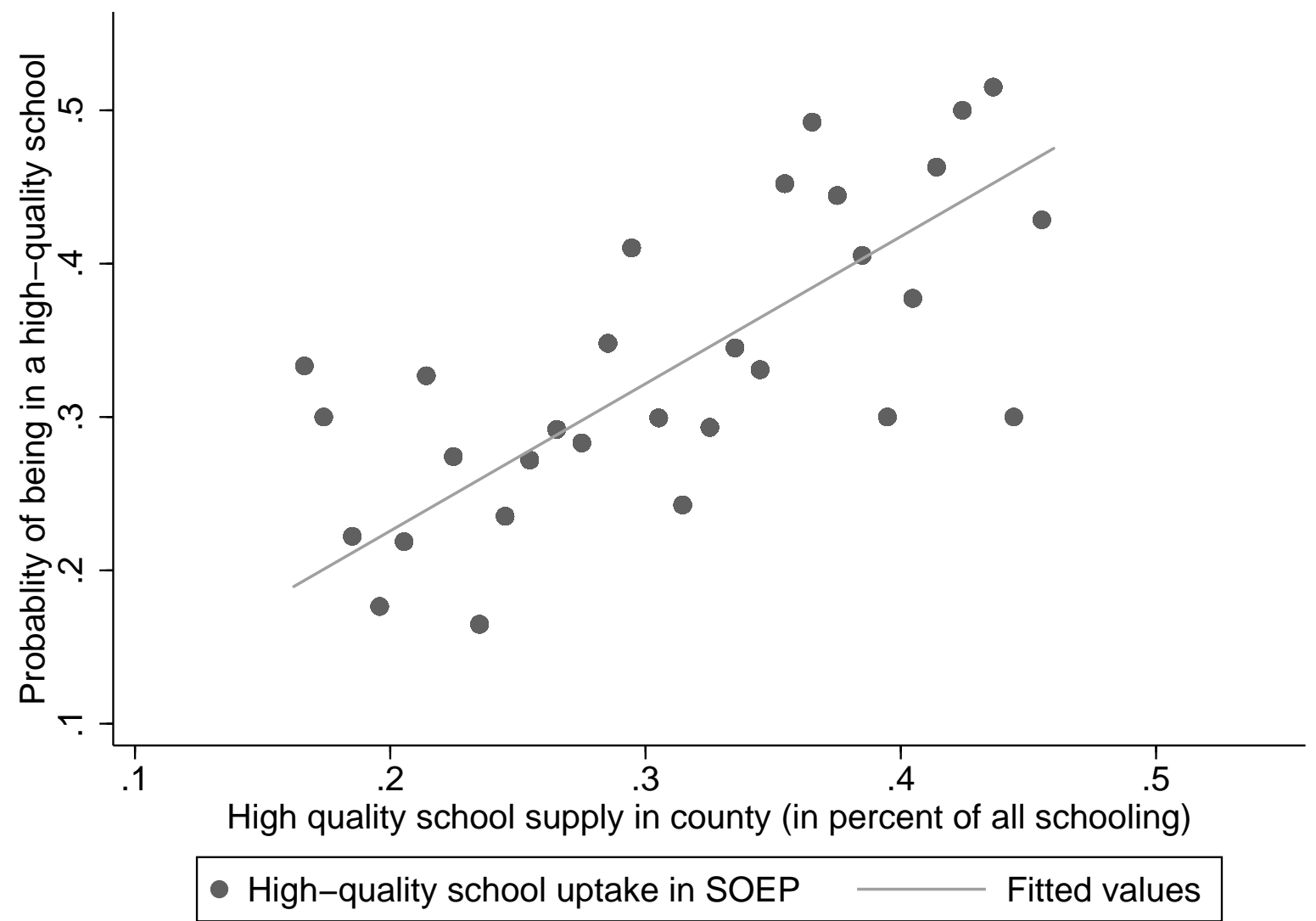

Notes: This figure graphically illustrates the relationship between the local availability of high-quality schools and the actual take up rate in the SOEP data. The horinzontal axis represents the percentage of all students in a county that can go to a high-quality school (versus schools of lower quality). We correlate those data against the observed take up rates of children in the SOEP. For that exercise, we track SOEP children into the counties that they where living in at the age of the school choice. Each point represents a bin of one percentage point in the $\mathrm{x}$-variable and the average take-up rate within this bin. We excluded bins below 16 and above 46 because sample size in those bins would have been to low (we mostly observe only one or two observations in those bins). The imposed line is fitted from a simple bivariate regression. Source: Own calculations.

In theory, school attendance could still be equally distributed independent of the local availability if children commute to other municipalities or counties. Figure 1 correlates the measure for the local supply within a county with the actual take-up rates in the SOEP. While there is variation around the trend, we observe a clear positive relationship between local supply and actual attendance. Similarly, table 2 shows that our instruments are relevant in the determination of the actual schooling decision. Irrespective of the parent's education or socio-economic status, the probability of observing a child attending a highquality school is always higher in a town with a locally available school or in a county with a higher share of locally supplied positions. 


\section{Results and discussion}

We present the results of our estimation and testing in two parts. First, we highlight and discuss the results from the regression control framework. We show the main results of the OLS estimation, discuss several checks for robustness and test for potential omitted variable bias using the AET method. Secondly, we illustrate the results of the IV estimations. Apart from the main results, we present reduced form and first stage results. Additionally, we apply the AET method also here; this time to evaluate the validity of the IV approach.

\subsection{Regression control framework}

The main results of the OLS estimations are presented in table 3 . Columns 1-3 present the estimation results for our first outcome variable: the intention to finish the Abitur. Columns 4-6 show the estimates for the outcome of whether the young adult plans to start a university education. In columns 1 and 4, we highlight the pure descriptive OLS effect using our treatment as a binary explanatory variable (the results correspond to the descriptives in table 1). In columns 2 and 4, we include our rich set of control variables and in the final columns we also specify state and cohort fixed effects.

Our treatment variable of whether a child attended a high-quality school is positive and significant for both outcomes and throughout all specifications. The effect on finishing the Abitur is as large as $56 \%$ in the pure difference. The number drops to about half once we control for our additional set of explanatory variables. However, it remains a sizable positive effect where attending a high-quality school changes the probability of planning to finish the Abitur by 28 percentage points. For the intention to start a university education, we report a similarly large estimate with about 22 percentage points.

Throughout all models, we find that the coefficients on the control variables fall in line with our expectations. We find that, female young adults are more likely to report plans for continued education, number of siblings have a negative effect, while parents education and household income exert a positive effect. Interestingly, whether parents show an interest in school issues is negatively related to both outcomes, indicating that parents get more involved if the children have problems. The most important variable for our outcome is the recommendation for a high-quality school, which is shown to be highly relevant for both outcomes 19

\footnotetext{
${ }^{19}$ Note that this is also the only variable that matters immensely for the point estimate of our treatment variable. Leaving this variable out of the regression control framework, we observe significantly larger treatment effects.
} 
Table 3: Main OLS results

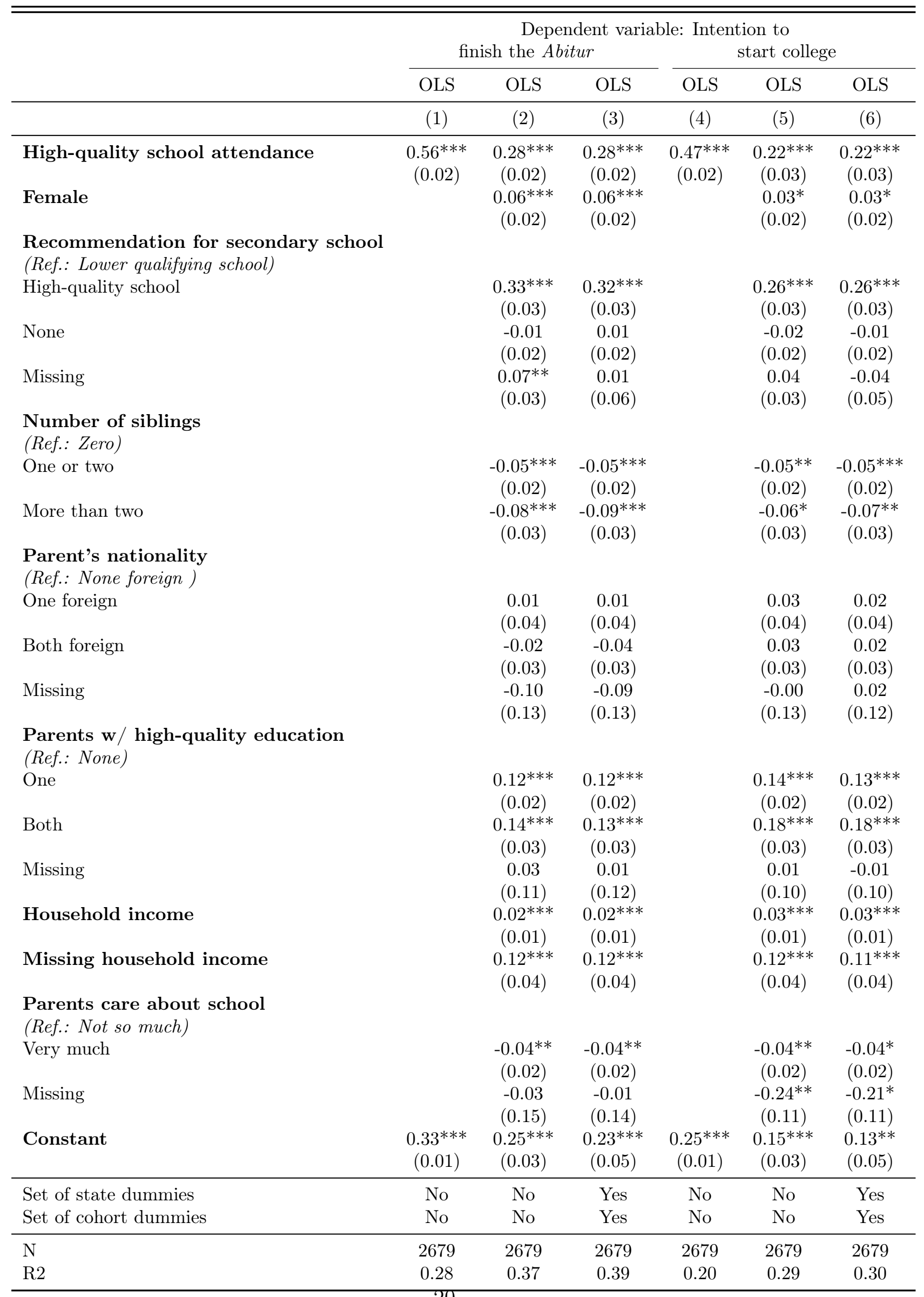

Source: Own calculations based on SOEP data.

Notes: $(* * * / * * / *)$ : indicates significance at the $1 \%-/ 5 \%-/ 10 \%$-level. Robust standard errors in parentheses. 
Table 4: Amount of selection on unobservables relative to selection on observables required to attribute the entire high-quality school effect to selection bias

\begin{tabular}{lcccccc}
\hline \hline & $\widehat{\operatorname{cov}}\left(X^{\prime} \beta, D\right) \div$ & \multicolumn{6}{c}{$\widehat{\operatorname{var}}\left(X^{\prime} \beta\right)$} & $\widehat{\operatorname{var}}(\epsilon)$ & $\widehat{\operatorname{var}}(\epsilon)$ & $\widehat{\operatorname{var}}(\widetilde{D})$ & $\begin{array}{c}\text { Implied } \\
\text { bias }\end{array}$ & Ratio \\
\hline & $(1)$ & $(2)$ & $(3)$ & $(4)$ & $(5)$ & $(6)$ \\
\hline Intention to & \multicolumn{7}{c}{ Panel A. Full set of observables } \\
finish the Abitur & 1.04 & 0.163 & 0.17 & 0.12 & 1.47 & 0.19 \\
start college & 1.196 & 0.177 & 0.212 & 0.12 & 1.83 & 0.15 \\
\hline & 0.574 & Panel B. Restricted set of observables & \\
finish the Abitur & 0.163 & 0.093 & 0.12 & 0.8 & 0.36 \\
start college & 0.618 & 0.229 & 0.141 & 0.12 & 1.22 & 0.18 \\
\hline
\end{tabular}

Source: Own calculations based on SOEP data.

Notes: For the restricted set of observables the variable teachers' recommendation has been eliminated from the set of observable using the Frisch-Waugh-Lovell-Theorem.

In table A4, we test variations of our models and further specifications. We evaluate how the estimates change if you estimate a probit instead, include the local population number in the regression, use county fixed effects instead of state fixed effects, use data for the former West only and reweight the sample using SOEP sampling weights. The estimates prove to be stable over the specifications.

Before we investigate the sensitivity of the OLS estimates to the influence of unobservable variables, we want to return to table A2. Here, we show descriptive statistics for our control variables by treatment status. The reported differences are often large and significant between the two samples. E.g., a child that has two parents with an Abitur is more likely to attend a high-quality school while children with foreign parents are less often observed in the treatment status. Thus, from observing the correlation between observables and the treatment variable we have little doubt that the OLS estimates are also potentially prone to influence by unobservables.

This observation is confirmed when we implement the AET method to check for the potential influence of unobservable characteristics. The results for this method are reported in table 4. We report all stages of the calculation, as introduced above (see section 4.3). In the interpretation, we focus on the last two columns. In column 5 , we report the implied bias. We find that the bias, calculated under the assumption of equality of selection on observables and unobservables is very large. Indeed, it is multiple times larger than our estimated coefficient in the OLS (being 28 (22) percentage point for our first (second) outcome). This is also indicated by the final column 6 in which we divide the coefficient from the OLS regression by the implied bias. This ratio has the following interpretation: Given 
the implied bias, selection on unobservables would need to be only $1 / 5(0.19)$ as strong as selection on observables to explain away the entire effect in the OLS. We, thus, have to consider it quite likely that the estimates in the regression control framework are indeed flawed by omitted variable bias.

Note that the implied bias itself should not be interpreted too strictly. This bias is calculated under the arguably strict assumption that selection on unobservables is in the same order as selection on observables. As Altonji et al. (2005a) argue themselves, this assumption really serves as an upper bound of the influence of unobservables and the actual degree is likely to fall short of that.

In panel 2 of table 4 we follow another recommendation of Altonji et al. (2005a) and exclude the secondary school recommendation from the set of observables when we apply the AET method. ${ }^{20}$ We do this, because the recommendation variable is unique in its influence on both treatment and outcomes. If we exclude this variable in the AET method, the results improve slightly, however, the OLS results are still likely to be significantly biased due to unobservable characteristics.

\subsection{Instrumental variable estimation}

In this section, we first highlight the results of the reduced form and the first stage for our two instrumental variables. In panel $\mathrm{A}$ of table 5 we show the estimates when we include the instruments (instead of the treatment) in the outcome equation. If the instruments are meaningful, we expect positive and significant estimates in this reduced form. In column 1 , we show the results for including our first instrument of whether a municipality has a local high-quality school within town borders. In the second column, we test our second instrument which is the share of school positions in high-quality schooling within a county. Finally, columns 3 and 4 show the estimates when we include both instruments simultaneously. We find sizable and significant effect for our first instrument on both outcomes. For our second instruments, the reduced form effect is not as strong and only sometimes significant.

Panel B of the same table shows the results of the first stage in the 2SLS estimation. We find that the local supply of high-quality schooling are important predictors of the attendance at such a school. Both instruments are positive and significant at the $5 \%$ level when included

\footnotetext{
${ }^{20}$ In practice, we first run a regression of all variables on the recommendation variable and then rerun the AET method with the residuals from those regressions. In their paper, Altonji et al. (2005a) suggest treating isolated variables in this specific way, if they present especially important variable in the determination of both treatment and outcome.
} 
Table 5: Reduced form and first-stage of the instrumental variable approach

\begin{tabular}{|c|c|c|c|c|}
\hline & \multirow[t]{2}{*}{ IV1 } & \multirow[t]{2}{*}{ IV2 } & \multicolumn{2}{|c|}{ IV1 \& IV2 } \\
\hline & & & IV1 & IV2 \\
\hline & (1) & $(2)$ & $(3)$ & $(4)$ \\
\hline & \multicolumn{4}{|c|}{ Panel A. Reduced Form } \\
\hline \multirow[t]{2}{*}{ Intention to finish the Abitur } & $0.036^{* *}$ & 0.089 & $0.038 * *$ & 0.012 \\
\hline & $(0.018)$ & $(0.120)$ & $(0.019)$ & $(0.127)$ \\
\hline \multirow[t]{2}{*}{ Intention to start college } & $0.050^{* * *}$ & $0.254^{* *}$ & $0.037^{*}$ & 0.167 \\
\hline & $(0.018)$ & $(0.123)$ & $(0.020)$ & $(0.130)$ \\
\hline \multirow{3}{*}{ High-quality school attendance at age 14} & \multicolumn{4}{|c|}{ Panel B. First stage } \\
\hline & $0.072^{* * *}$ & $0.359 * * *$ & $0.066^{* * *}$ & $0.237^{* *}$ \\
\hline & $(0.013)$ & $(0.087)$ & $(0.014)$ & $(0.093)$ \\
\hline Personal characteristics & Yes & Yes & Yes & Yes \\
\hline Set of state dummies & Yes & Yes & Yes & Yes \\
\hline Set of cohort dummies & Yes & Yes & Yes & Yes \\
\hline F-value of instruments & 24.90 & 11.36 & \multicolumn{2}{|c|}{15.98} \\
\hline Partial $R^{2}$ & 0.010 & 0.004 & \multicolumn{2}{|c|}{0.013} \\
\hline Hansen J statistic: Finishing the Abitur & & & \multirow{2}{*}{\multicolumn{2}{|c|}{$\begin{array}{c}0.362 \\
(0.548)\end{array}$}} \\
\hline p-value & & & & \\
\hline Hansen J statistic: Starting college & & & \multicolumn{2}{|c|}{0.205} \\
\hline p-value & & & \multicolumn{2}{|c|}{$(0.651)$} \\
\hline
\end{tabular}

Source: Own calculations based on SOEP data.

Notes: $(* * * / * * / *)$ : indicates significance at the 1\%-/5\%-/10\%-level. Robust standard errors in parentheses.

in the first stage. The F-statistic on the instruments is well above 10 and the Hansen J statistic (when we include both instruments) signals that our instruments can indeed be excluded from the outcome equation. Note that, all reduced form and first stage regressions include the full set of additional control variables.

The main results of the IV approaches are presented in table 6. We show the results of the two outcome variables in columns 1-3 and 4-6 respectively. At the top of table, we indicate whether we use our first instrument, our second instrument or both. All 2SLS estimations include the full set of additional controls. For the results in column 2 and 5 it must be kept in mind that the reduced form and the first-stage diagnostics point to a weak instrument problem. This is also indicated by the higher standard errors when using the second IV.

The results for the treatment effects in the 2SLS are positive and mostly significant. For the intention to finish the Abitur, we find point estimates that range between 29 and 49 percentage points. The results are significant at the $5 \%$ level when we include our first IV, but insignificant when only the second IV is included (this corresponds directly to the results in the reduced form, see table 5). This estimates are notably larger than our findings for OLS. This is also true for the second outcome variable which is the stated preference 
to continue education on the tertiary level. Here, our significant point estimates range between 58 to 75 percentage points.

Overall, the IV strategies give highly significant and strongly positive results. Also the reduced form and first stage estimates speak in favor of the analysis. However, we find the size of the IV estimates to be implausibly large. The arguments in the literature have mostly pointed to an upward-bias of the OLS due to omitted variables such as the child's true ability or the motivation of the parents, hence, an even larger effect of the IV estimates is surprising.

How could those large IV estimates be reconciled? ${ }^{21}$ One argument could be that the nature of the instrument leads to a very specific local average treatment effect (LATE) that is being estimated. The presented instruments estimate a LATE that will effectively compare the marginally treated to those that are marginally non-treated. In terms of the expected peer effects from attending a high-quality school, one could argue that the marginally treated have the most to gain from attending one, while those that are marginally non-treated have the most to lose. However, we find it hard to believe that this could explain such a large positive difference with the transition from the OLS to the IV. To investigate this issue further, we continue to carefully test for bias in the IV estimation that may explain the large effects.

Before we test for the validity of the instrument using the AET method, we again draw the attention to the simple comparison of means in table A3. Similar to above, we here show the characteristics of our observed variables, this time, by the two categories of our first instrument. If the assumptions holds that our instruments are independent of unobservables, we should expect little to no correlation of the instrument with our observables. While it is true that our instrument varies much less with the observables than the treatment variable (see table A2), we still find some significant differences. Our instrument varies significantly with parent's education as well as parent's nationality, which is worrisome for our analysis.

The AET method formalizes this test and evaluates the validity of the instrument under the assumption that selection on the unobservables is equal to selection on observables. The results of this test are shown in table 7. Again, we present every step of the derivation. For interpretation, we focus on column 6 . We find that our instruments cannot pass the

${ }^{21}$ In the literature on the effect of schooling on earnings, the finding that IV-estimates are larger than estimates from OLS is a common pattern. Researchers usually argue that the smaller effect measured in OLS stems from measurement error in the explanatory variable. In most studies this variable is years of education and the information is asked retrospectively. However, for our explanatory variable, a child's attendance at a high-quality school is reported by the parents in the respective year, what makes a significant measurement error unlikely. 
Table 6: Main IV results

\begin{tabular}{|c|c|c|c|c|c|c|}
\hline & \multicolumn{6}{|c|}{ Dependent variable: Intention to } \\
\hline & \multicolumn{3}{|c|}{ finish the Abitur } & \multicolumn{3}{|c|}{ start college } \\
\hline & IV1 & IV2 & IV1 \& IV2 & IV1 & IV2 & IV1 \& IV2 \\
\hline & $(1)$ & $(2)$ & $(3)$ & (4) & $(5)$ & (6) \\
\hline High-quality school attendance & $\begin{array}{c}0.49^{* *} \\
(0.23)\end{array}$ & $\begin{array}{c}0.29 \\
(0.34)\end{array}$ & $\begin{array}{l}0.45^{* *} \\
(0.20)\end{array}$ & $\begin{array}{c}0.65^{* * *} \\
(0.25)\end{array}$ & $\begin{array}{l}0.75^{* *} \\
(0.38)\end{array}$ & $\begin{array}{c}0.58^{* * *} \\
(0.22)\end{array}$ \\
\hline Female & $\begin{array}{c}0.06^{* * *} \\
(0.02)\end{array}$ & $\begin{array}{c}0.06^{* * *} \\
(0.02)\end{array}$ & $\begin{array}{c}0.06^{* * *} \\
(0.02)\end{array}$ & $\begin{array}{c}0.02 \\
(0.02)\end{array}$ & $\begin{array}{c}0.02 \\
(0.02)\end{array}$ & $\begin{array}{c}0.02 \\
(0.02)\end{array}$ \\
\hline \multicolumn{7}{|c|}{$\begin{array}{l}\text { Recommendation for secondary school } \\
\text { (Ref.: Lower qualifying school) }\end{array}$} \\
\hline High-quality school & $\begin{array}{c}0.20 \\
(0.14)\end{array}$ & $\begin{array}{c}0.32 \\
(0.21)\end{array}$ & $\begin{array}{l}0.22^{*} \\
(0.13)\end{array}$ & $\begin{array}{c}0.01 \\
(0.15)\end{array}$ & $\begin{array}{l}-0.06 \\
(0.23)\end{array}$ & $\begin{array}{c}0.05 \\
(0.14)\end{array}$ \\
\hline None & $\begin{array}{c}0.01 \\
(0.03)\end{array}$ & $\begin{array}{c}0.01 \\
(0.03)\end{array}$ & $\begin{array}{c}0.01 \\
(0.03)\end{array}$ & $\begin{array}{l}-0.02 \\
(0.03)\end{array}$ & $\begin{array}{l}-0.03 \\
(0.03)\end{array}$ & $\begin{array}{l}-0.01 \\
(0.02)\end{array}$ \\
\hline Missing & $\begin{array}{l}-0.03 \\
(0.06)\end{array}$ & $\begin{array}{c}0.01 \\
(0.07)\end{array}$ & $\begin{array}{l}-0.02 \\
(0.06)\end{array}$ & $\begin{array}{l}-0.10 \\
(0.07)\end{array}$ & $\begin{array}{l}-0.12 \\
(0.08)\end{array}$ & $\begin{array}{l}-0.09 \\
(0.07)\end{array}$ \\
\hline \multicolumn{7}{|l|}{$\begin{array}{l}\text { Number of siblings } \\
\text { (Ref.: Zero) }\end{array}$} \\
\hline One or two & $\begin{array}{c}-0.05^{* * *} \\
(0.02)\end{array}$ & $\begin{array}{c}-0.05^{* * *} \\
(0.02)\end{array}$ & $\begin{array}{c}-0.05^{* * *} \\
(0.02)\end{array}$ & $\begin{array}{c}-0.05^{* *} \\
(0.02)\end{array}$ & $\begin{array}{c}-0.05^{* *} \\
(0.02)\end{array}$ & $\begin{array}{c}-0.05^{* *} \\
(0.02)\end{array}$ \\
\hline More than two & $\begin{array}{c}-0.08^{* *} \\
(0.03)\end{array}$ & $\begin{array}{c}-0.09 * * * \\
(0.03)\end{array}$ & $\begin{array}{c}-0.08^{* *} \\
(0.03)\end{array}$ & $\begin{array}{l}-0.04 \\
(0.03)\end{array}$ & $\begin{array}{l}-0.04 \\
(0.04)\end{array}$ & $\begin{array}{l}-0.05 \\
(0.03)\end{array}$ \\
\hline \multicolumn{7}{|l|}{$\begin{array}{l}\text { Parent's nationality } \\
\text { (Ref.: None foreign) }\end{array}$} \\
\hline One foreign & $\begin{array}{c}0.01 \\
(0.04)\end{array}$ & $\begin{array}{c}0.02 \\
(0.04)\end{array}$ & $\begin{array}{c}0.02 \\
(0.04)\end{array}$ & $\begin{array}{c}0.01 \\
(0.05)\end{array}$ & $\begin{array}{c}0.01 \\
(0.05)\end{array}$ & $\begin{array}{c}0.02 \\
(0.04)\end{array}$ \\
\hline Both foreign & $\begin{array}{l}-0.01 \\
(0.04)\end{array}$ & $\begin{array}{l}-0.03 \\
(0.04)\end{array}$ & $\begin{array}{l}-0.02 \\
(0.04)\end{array}$ & $\begin{array}{c}0.06 \\
(0.04)\end{array}$ & $\begin{array}{c}0.07 \\
(0.04)\end{array}$ & $\begin{array}{c}0.05 \\
(0.04)\end{array}$ \\
\hline Missing & $\begin{array}{l}-0.09 \\
(0.16)\end{array}$ & $\begin{array}{l}-0.04 \\
(0.15)\end{array}$ & $\begin{array}{l}-0.05 \\
(0.16)\end{array}$ & $\begin{array}{c}0.08 \\
(0.15)\end{array}$ & $\begin{array}{c}0.19 \\
(0.15)\end{array}$ & $\begin{array}{c}0.14 \\
(0.14)\end{array}$ \\
\hline \multicolumn{7}{|l|}{$\begin{array}{l}\text { Parents w/ high-quality education } \\
\text { (Ref.: None) }\end{array}$} \\
\hline One & $\begin{array}{c}0.10^{* * *} \\
(0.03)\end{array}$ & $\begin{array}{c}0.12^{* * *} \\
(0.04)\end{array}$ & $\begin{array}{c}0.10^{* * *} \\
(0.03)\end{array}$ & $\begin{array}{c}0.09^{* * *} \\
(0.03)\end{array}$ & $\begin{array}{r}0.08^{* *} \\
(0.04)\end{array}$ & $\begin{array}{c}0.10^{* * *} \\
(0.03)\end{array}$ \\
\hline Both & $\begin{array}{c}0.09^{* *} \\
(0.05)\end{array}$ & $\begin{array}{c}0.13^{* *} \\
(0.07)\end{array}$ & $\begin{array}{c}0.10^{* *} \\
(0.04)\end{array}$ & $\begin{array}{l}0.10^{*} \\
(0.05)\end{array}$ & $\begin{array}{c}0.09 \\
(0.08)\end{array}$ & $\begin{array}{c}0.11^{* *} \\
(0.05)\end{array}$ \\
\hline Missing & $\begin{array}{c}0.01 \\
(0.14)\end{array}$ & $\begin{array}{l}-0.03 \\
(0.14)\end{array}$ & $\begin{array}{l}-0.03 \\
(0.15)\end{array}$ & $\begin{array}{l}-0.07 \\
(0.14)\end{array}$ & $\begin{array}{l}-0.17 \\
(0.13)\end{array}$ & $\begin{array}{l}-0.12 \\
(0.12)\end{array}$ \\
\hline Household income & $\begin{array}{l}0.01 \\
(0.01)\end{array}$ & $\begin{array}{c}0.02 \\
(0.01)\end{array}$ & $\begin{array}{l}0.01^{*} \\
(0.01)\end{array}$ & $\begin{array}{l}0.02^{*} \\
(0.01)\end{array}$ & $\begin{array}{c}0.01 \\
(0.01)\end{array}$ & $\begin{array}{l}0.02^{* *} \\
(0.01)\end{array}$ \\
\hline Missing household income & $\begin{array}{c}0.12^{* * *} \\
(0.04)\end{array}$ & $\begin{array}{c}0.12^{* * *} \\
(0.04)\end{array}$ & $\begin{array}{c}0.12^{* * *} \\
(0.04)\end{array}$ & $\begin{array}{c}0.09^{* *} \\
(0.05)\end{array}$ & $\begin{array}{l}0.09^{*} \\
(0.05)\end{array}$ & $\begin{array}{c}0.10^{* *} \\
(0.05)\end{array}$ \\
\hline $\begin{array}{l}\text { Parents care about school } \\
\text { (Ref.: Not so much) }\end{array}$ & & & & & & \\
\hline Very much & $\begin{array}{c}-0.04^{*} \\
(0.02)\end{array}$ & $\begin{array}{l}-0.03 \\
(0.02)\end{array}$ & $\begin{array}{l}-0.03 \\
(0.02)\end{array}$ & $\begin{array}{l}-0.02 \\
(0.02)\end{array}$ & $\begin{array}{l}-0.02 \\
(0.02)\end{array}$ & $\begin{array}{l}-0.02 \\
(0.02)\end{array}$ \\
\hline Missing & $\begin{array}{l}0.00 \\
(0.16)\end{array}$ & $\begin{array}{c}0.01 \\
(0.15)\end{array}$ & $\begin{array}{c}0.01 \\
(0.15)\end{array}$ & $\begin{array}{l}-0.18 \\
(0.16)\end{array}$ & $\begin{array}{l}-0.17 \\
(0.17)\end{array}$ & $\begin{array}{l}-0.18 \\
(0.15)\end{array}$ \\
\hline Constant & $\begin{array}{c}0.25^{* * *} \\
(0.05)\end{array}$ & $\begin{array}{c}0.27^{* * *} \\
(0.05)\end{array}$ & $\begin{array}{c}0.26^{* * *} \\
(0.05)\end{array}$ & $\begin{array}{c}0.17^{* * *} \\
(0.05)\end{array}$ & $\begin{array}{c}0.17^{* * *} \\
(0.05)\end{array}$ & $\begin{array}{c}0.17^{* * *} \\
(0.05)\end{array}$ \\
\hline Set of state dummies & Yes & Yes & Yes & Yes & Yes & Yes \\
\hline Set of cohort dummies & Yes & Yes & Yes & Yes & Yes & Yes \\
\hline $\mathrm{N}$ & 2605 & 2592 & 2521 & 2605 & 2592 & 2521 \\
\hline $\mathrm{R} 2$ & 0.34 & 0.34 & 0.35 & 0.20 & 0.18 & 0.23 \\
\hline
\end{tabular}

Source: Own calculations based on SOEP data.

Notes: $(* * * / * * / *)$ : indicates significance at the $1 \%^{-} / 5 \%^{-} / 10 \%$-level. Robust standard errors in parentheses. 
Table 7: IV Estimation: Amount of selection on unobservables relative to selection on observables required to attribute the entire high-quality school effect to selection bias

\begin{tabular}{|c|c|c|c|c|c|c|c|}
\hline & $\begin{array}{c}\widehat{\operatorname{cov}}\left(X^{\prime} \beta, Z\right) \div \\
\widehat{\operatorname{var}}\left(X^{\prime} \beta\right)\end{array}$ & $\widehat{\operatorname{var}}(\epsilon)$ & $\begin{array}{c}\widehat{\operatorname{cov}}(\epsilon, Z) \div \\
\widehat{\operatorname{var}}(\epsilon)\end{array}$ & $\lambda$ & $\widehat{\operatorname{var}}(\widetilde{Z})$ & $\begin{array}{l}\text { Implied } \\
\text { bias }\end{array}$ & Ratio \\
\hline & (1) & $(2)$ & (3) & (4) & $(5)$ & (6) & (7) \\
\hline \multicolumn{8}{|l|}{ Intention to } \\
\hline finish the Abitur & 0.208 & 0.162 & $\begin{array}{l}\text { Panel A. } \\
0.034\end{array}$ & $\begin{array}{l}I V 1 \\
0.076\end{array}$ & 0.203 & 2.18 & 0.221 \\
\hline start college & 0.226 & 0.177 & 0.041 & 0.076 & 0.203 & 2.59 & 0.251 \\
\hline finish the Abitur & 0.026 & 0.162 & $\begin{array}{l}\text { Panel B. } \\
0.004\end{array}$ & $\begin{array}{l}I V 2 \\
0.340\end{array}$ & 0.005 & 2.71 & 0.176 \\
\hline start college & 0.027 & 0.176 & 0.005 & 0.340 & 0.005 & 3.08 & 0.180 \\
\hline
\end{tabular}

Source: Own calculations based on SOEP data.

Notes: For the restricted set of observables the variable teachers' recommendation has been eliminated from the set of observable using the Frisch-Waugh-Lovell-Theorem.

test and that the implied bias calculated by the AET method exceeds the point estimates of the IV regressions. The degree to which our instruments vary with the observed factors is still too large to plausibly argue that a correlation of the instrument with unobserved characteristics would not be influential.

How can this finding be explained? Comparing column 1 of table 7 to the same column of table 4, we see that the correlation of the instrument with the index of observables is much less than the correlation of treatment with that index. However, in the bias formulation of the IV, we also have to divide by the first stage estimates (see eq. 10). Even if the instruments show less correlation with the observables, the implied bias in the IV estimation is inflated by the small first stage estimate and ends up being even bigger than in the OLS.

In the end, the AET method highlights that both the OLS and the IV are prone to bias due to selection on unobservables in the application at hand. This result hinges on the strict assumption that we can learn about the implied bias induced by unobservables by carefully analysing how treatment (or the instrument) relate to the observable characteristics. If we would observe no or little correlation here, we would have reason to argue that the influence of unobservables is unlikely to affect the results. However, we observe significant correlation between the observables and both our treatment and instruments. 


\section{Conclusions}

This paper studies the effect of attending a high-quality secondary school on further educational outcomes. The specific focus of the paper is on the potential influence of selection on unobservables that is likely to affect the estimation of that treatment effect. Methodologically, we first use regression-control framework as well as instrumental variable techniques. We then carefully evaluate the influence of unobservable characteristics in both methods using the technique proposed by Altonji et al. (2005b a). This methodology draws conclusion based on the assumption of equality of selection on observables and unobservables.

The analysis is based on an extended database that connects information of the German Socio-Economic Panel with administrative data of local school supply in a municipality and/or the county. We observe children at the age of 10-12 when they make their secondary school choice (conditional on local supply) and are able to follow them through the age of 16-17 when they self-assess their future educational plans. Specifically, we can investigate the treatment effect of attending a high-quality school on the self-reported intention to finish the Abitur as well as the intend to seek post-secondary, university education

In the first part of the empirical results, we analyze the effect of attending a high-quality school in a regression-control framework. Using detailed control variables at the individual and household level, we report very large and significantly positive effects of the treatment. However, these large effects are then shown to be potentially driven by selection on unobservables. The AET method indicates that even a modest degree of selection of unobservables (relative to selection on the observables) would suffice to explain away the entire effect. These results clearly highlight why researchers are sceptical of using simple OLS techniques to address this research question.

In the second part, we turn to instrumental variable approaches in which we instrument high-quality school attendance with the local supply of such schools. Specifically, we collected data on (1) an indicator whether the child's home town has a high-quality school within town borders and (2) a variable for the share of high-quality school positions within the local county. Results of the instrumental variable estimations also point us to large and significant treatment effects of attending a high-quality school. Moreover, traditional first stage diagnostics as well as the reduced form estimations show that the first instrument is relevant. The second instrument is prone to be a weak instrument.

However, even in the instrumental variable approach we fail to pass the test provided by the AET method. When we evaluate the validity of the IV approaches using this method, we again detect excessive correlation of the instrument with observable characteristics that 
leads us to the conclusion that an important bias from unobservables cannot be ruled out. This is a surprising result given that a large literature is interested both on the direct effects of proximity to educational institutions as well as on the use of such variables as instruments.

Finally, in terms of policy relevance we should carefully avoid to draw the wrong conclusions from our results. We can only highlight that conventional methods and our instrumental variables approaches are prone to bias from selection on unobservables. That does not imply that the bias from omitted variables cannot in fact be very small and that attending a high-quality school still has a positive and large effect on further educational outcomes. However, to prove such a causal relationship, further research is needed.

\section{References}

Altonji, J. G., T. E. Elder, And C. R. Taber (2005a): "An Evaluation of Instrumental Variable Strategies for Estimating the Effects of Catholic Schooling," The Journal of Human Resources, 40, 791-821.

(2005b): "Selection on Observed and Unobserved Variables: Assessing the Effectiveness of Catholic Schools," Journal of Political Economy, 113, 151-184.

Ammermueller, A. And J. Pischke (2009): "Peer Effects in European Primary Schools: Evidence from the Progress in International Reading Literacy Study," Journal of Labor Economics, 27, 315-348.

Bayer, P., F. Ferreira, And R. McMillan (2007): "A Unified Framework for Measuring Preferences for Schools and Neighborhoods," Journal of Political Economy, $115,588-638$.

Bifulco, R., J. M. Fletcher, And S. L. Ross (2011): "The Effect of Classmate Characteristics on Post-Secondary Outcomes: Evidence from the Add Health," American Economic Journal: Economic Policy, 3, 25-53.

Black, S. E. (1999): "Do Better Schools Matter? Parental Valuation of Elementary Education," The Quarterly Journal of Economics, 114, 577-599.

Brunello, G. And D. Checchi (2007): "Does School Tracking Affect Equality of Opportunity? New International Evidence," Economic Policy, 22, 781-861.

CARD, D. (1995): "Using Geographical Variation in College Proximity to Estimate the Returns to Schooling," in Aspects of Labour Market Behavior: Essays in Honour of John Vanderkamp, ed. by L. N. Christofides, E. K. Grant, and R. Swidinsky, Toronto. 
Denzler, S. And S. C. Wolter (2011): "Too Far to Go? Does Distance Determine Study Choices?" Discussion Paper Series 5712, Forschungsinstitut zur Zukunft der Arbeit.

Do, C. (2004): "The Effects of Local Colleges on the Quality of College Attended," Economics of Education Review, 23, 249 - 257.

Dustmann, C., P. A. Puhani, And U. Schönberg (2012): "The Long-term Effects of School Quality on Labor Market Outcomes and Educational Attainment," CReAM Discussion Paper Series 1208, Centre for Research and Analysis of Migration (CReAM), Department of Economics, University College London.

Evans, W. N. And R. M. Schwab (1995): "Finishing High School and Starting College: Do Catholic Schools Make a Difference?" The Quarterly Journal of Economics, 110, 941-974.

Falch, T., P. Lujala, And B. Strøm (2011): "Geographical Constraints and Educational Attainment," Working paper series, Department of Economics, Norwegian University of Science and Technology.

Frenette, M. (2006): "Too Far to Go On? Distance to School and University Participation," Education Economics, 14, 31-58.

_ (2009): "Do Universities Benefit Local Youth? Evidence from the Creation of New Universities," Economics of Education Review, 28, 318 - 328.

Gould, E. D., V. Lavy, And M. Paserman (2009): "Does Immigration Affect the Long-Term Educational Outcomes of Natives? Quasi-Experimental Evidence," The Economic Journal, 119, 1243-1269.

HanusheK, E. A. And L. Wössmann (2006): "Does Educational Tracking Affect Performance and Inequality? Differences- in-Differences Evidence Across Countries," Economic Journal, 116, C63-C76.

HoxBy, C. (2000): "Peer Effects in the Classroom: Learning from Gender and Race Variation," Working Paper 7867, National Bureau of Economic Research.

Lavy, V., O. Silva, And F. Weinhardt (2012): "The Good, the Bad, and the Average: Evidence on Ability Peer Effects in Schools," Journal of Labor Economics, 30, 367-414.

Lohmann, H. And O. Groh-SAmberG (2010): "Akzeptanz von Grundschulempfehlungen und Auswirkungen auf den weiteren Bildungsverlauf," Zeitschrift für Soziologie, 39, 470-492.

NEAL, D. (1997): "The Effects of Catholic Secondary Schooling on Educational Achievement," Journal of Labor Economics, 15, 98-123.

Rosenbaum, P. R. (1995): Observational Studies, Springer Verlag. New York.

Schneeweis, N. And R. Winter-Ebmer (2007): "Peer effects in Austrian Schools," Empirical Economics, 32, 387-409. 
Spiess, C. K. And K. Wrohlich (2010): "Does Distance Determine who Attends a University in Germany?" Economics of Education Review, 29, 470-479.

VArdardottir, A. (2012): "Peer Effects and Academic Achievement-Regression Discontinuity Approach," http://www.iza.org/conferencefiles/SUMS2012/vardardottiera7647.pdf.

Virtanen, H. And L. VÄÄnÄnen (2010): "Supply of Education and Schooling Choices," mimeo, http://2010.economicsofeducation.com/user/pdfsesiones/100.pdf. 


\section{Appendix}

Table A1: Age and year of observation

\begin{tabular}{lcccc}
\hline \hline & & \multicolumn{3}{c}{ Year of observation } \\
\cline { 3 - 5 } Age & Total & $1992-1996$ & $1997-2001$ & $2002-2007$ \\
\hline 8 & 2 & 0 & 2 & 0 \\
9 & 61 & 22 & 34 & 5 \\
10 & 657 & 218 & 298 & 141 \\
11 & 868 & 219 & 406 & 243 \\
12 & 655 & 73 & 387 & 195 \\
13 & 246 & 8 & 172 & 66 \\
14 & 190 & 0 & 131 & 59 \\
\hline Total & 2,679 & 540 & 1,430 & 709 \\
\hline
\end{tabular}

Notes: The table shows the composition of the sample over time and by the age at which we observe the child with her initial schooling decision.

Source: Own calculations based on SOEP data. 
Figure B1: Number of high-quality schools over time

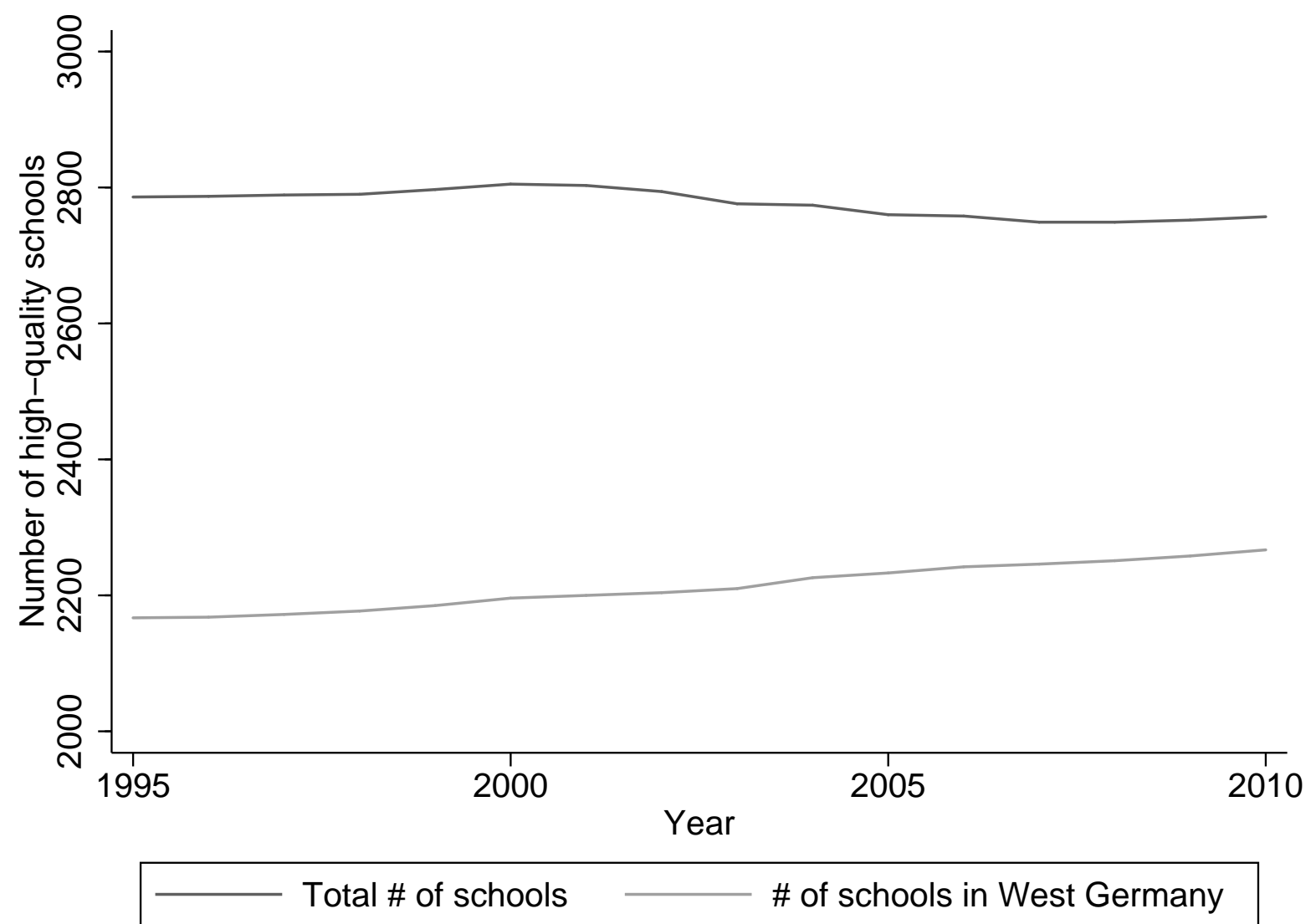

Notes: In this figure, we highlight the development in the number of high-quality schools in Germany for the time period between 1995 and 2010. The upper line shows the total number of high-quality schools in each respective year. The lower line illustrates the development within the West of Germany. Source: Own calculations based on data from "Statistik Regional" 
Table A2: Descriptive statistics by high-quality school take-up

\begin{tabular}{|c|c|c|c|c|c|c|}
\hline & \multicolumn{6}{|c|}{ High-quality school attendance } \\
\hline & \multicolumn{2}{|c|}{ no } & \multicolumn{2}{|c|}{ yes } & \multirow[b]{3}{*}{ Diff. } & \multirow[b]{3}{*}{ T-test } \\
\hline \multirow[t]{2}{*}{ Total \# of obs } & \multicolumn{2}{|c|}{1732} & \multicolumn{2}{|c|}{864} & & \\
\hline & Share & S.E & Share & S.E & & \\
\hline Female & 0.47 & 0.50 & 0.54 & 0.50 & $-0.074^{* * *}$ & -3.56 \\
\hline \multicolumn{7}{|l|}{ Parents w/ high-quality education } \\
\hline None & 0.80 & 0.40 & 0.48 & 0.50 & $0.32^{* * *}$ & 17.41 \\
\hline One & 0.13 & 0.34 & 0.27 & 0.45 & $-0.14^{* * *}$ & -8.91 \\
\hline Both & 0.05 & 0.21 & 0.23 & 0.42 & $-0.19^{* * *}$ & -14.94 \\
\hline Missing & 0.02 & 0.14 & 0.01 & 0.11 & 0.009 & 1.54 \\
\hline \multicolumn{7}{|l|}{ Socio-Economic Status (isei scale) } \\
\hline Low & 0.46 & 0.50 & 0.24 & 0.43 & $0.22^{* * *}$ & 11.10 \\
\hline High & 0.42 & 0.49 & 0.72 & 0.45 & $-0.30 * * *$ & -14.94 \\
\hline Missing & 0.12 & 0.33 & 0.04 & 0.21 & $0.08^{* * *}$ & 6.43 \\
\hline \multicolumn{7}{|l|}{ Parents's nationality } \\
\hline None foreign & 0.82 & 0.39 & 0.92 & 0.27 & $-0.10^{* * *}$ & -6.93 \\
\hline One foreign & 0.04 & 0.20 & 0.05 & 0.21 & -0.00 & -0.15 \\
\hline Both foreign & 0.12 & 0.33 & 0.03 & 0.16 & $0.10^{* * *}$ & 8.16 \\
\hline Missing & 0.02 & 0.13 & 0.01 & 0.10 & 0.01 & 1.42 \\
\hline \multicolumn{7}{|l|}{ Number of Siblings } \\
\hline Zero & 0.26 & 0.44 & 0.26 & 0.44 & -0.00 & -0.25 \\
\hline One or two & 0.65 & 0.48 & 0.68 & 0.47 & -0.03 & -1.60 \\
\hline More than two & 0.10 & 0.29 & 0.06 & 0.24 & $0.04^{* *}$ & 3.15 \\
\hline \multicolumn{7}{|l|}{ Recommendation for secondary schoo } \\
\hline Lower-quality school & 0.57 & 0.50 & 0.09 & 0.28 & $0.48^{* * *}$ & 26.37 \\
\hline High-quality school & 0.13 & 0.34 & 0.79 & 0.41 & $-0.66^{* * *}$ & -43.43 \\
\hline No recommendation & 0.20 & 0.40 & 0.05 & 0.22 & $0.15^{* * *}$ & 10.35 \\
\hline Missing & 0.10 & 0.30 & 0.08 & 0.27 & $0.03^{*}$ & 2.08 \\
\hline \multicolumn{7}{|l|}{ Parents care about school } \\
\hline Not so much & 0.23 & 0.42 & 0.26 & 0.44 & -0.03 & -1.76 \\
\hline Very much & 0.77 & 0.42 & 0.74 & 0.44 & 0.03 & 1.76 \\
\hline Household Income (mean in Euro) & 2377 & 1187 & 3233 & 1735 & $-868.1^{* * *}$ & -14.41 \\
\hline
\end{tabular}

Source: Own calculations based on SOEP data.

Notes: Low socio-economic status: isei score below 43 (out of 90). 
Table A3: Descriptive statistics by instrumental variable

\begin{tabular}{|c|c|c|c|c|c|c|}
\hline \multirow{4}{*}{ Total \# of obs } & \multicolumn{6}{|c|}{$\begin{array}{c}\text { IV1 } \\
\text { Municipality }\end{array}$} \\
\hline & \multicolumn{2}{|c|}{$\begin{array}{c}\text { w/o high-quality } \\
\text { school }\end{array}$} & \multicolumn{2}{|c|}{$\begin{array}{l}\text { w/ high-quality } \\
\text { school }\end{array}$} & \multirow[b]{3}{*}{ Diff. } & \multirow[b]{3}{*}{ T-test } \\
\hline & \multicolumn{2}{|c|}{1048} & \multicolumn{2}{|c|}{1548} & & \\
\hline & Share & S.E & Share & S.E & & \\
\hline Female & 0.49 & 0.50 & 0.50 & 0.50 & -0.011 & -0.55 \\
\hline Parents w/ high-quality education & & & & & & \\
\hline None & 0.73 & 0.44 & 0.67 & 0.47 & $0.064^{* * *}$ & 3.48 \\
\hline One & 0.17 & 0.37 & 0.19 & 0.39 & -0.019 & -1.26 \\
\hline Both & 0.08 & 0.28 & 0.12 & 0.33 & $-0.038^{* *}$ & -3.04 \\
\hline Missing & 0.01 & 0.12 & 0.02 & 0.14 & -0.007 & -1.30 \\
\hline Socio-Economic Status (isei scale) & & & & & & \\
\hline Low & 0.43 & 0.50 & 0.36 & 0.48 & $0.075^{* * *}$ & 3.88 \\
\hline High & 0.50 & 0.50 & 0.53 & 0.50 & -0.031 & -1.53 \\
\hline Missing & 0.07 & 0.25 & 0.12 & 0.32 & $-0.045^{* * *}$ & -3.80 \\
\hline Parents's nationality & & & & & & \\
\hline None foreign & 0.91 & 0.29 & 0.81 & 0.39 & $0.095^{* * *}$ & 6.78 \\
\hline One foreign & 0.04 & 0.19 & 0.05 & 0.22 & -0.012 & -1.44 \\
\hline Both foreign & 0.05 & 0.21 & 0.12 & 0.32 & $-0.07 * * *$ & -6.45 \\
\hline Missing & 0.01 & 0.09 & 0.02 & 0.13 & $-0.01^{*}$ & -2.24 \\
\hline Number of Siblings & & & & & & \\
\hline Zero & 0.24 & 0.43 & 0.27 & 0.44 & -0.03 & -1.73 \\
\hline One or two & 0.67 & 0.47 & 0.65 & 0.48 & 0.02 & 1.27 \\
\hline More than two & 0.09 & 0.28 & 0.08 & 0.27 & 0.01 & 0.55 \\
\hline Recommendation for secondary sch & & & & & & \\
\hline Lower-quality school & 0.41 & 0.49 & 0.40 & 0.49 & 0.01 & 0.45 \\
\hline High-quality school & 0.30 & 0.46 & 0.38 & 0.48 & $-0.07 * * *$ & -3.87 \\
\hline No recommendation & 0.17 & 0.38 & 0.14 & 0.34 & $0.03^{*}$ & 2.26 \\
\hline Missing & 0.11 & 0.32 & 0.08 & 0.27 & $0.03^{* *}$ & 2.80 \\
\hline Parents care about school & & & & & & \\
\hline Not so much & 0.25 & 0.43 & 0.23 & 0.42 & 0.0158 & 0.93 \\
\hline Very much & 0.75 & 0.43 & 0.77 & 0.42 & -0.0158 & -0.93 \\
\hline Household Income (mean in Euro) & 2512 & 1147 & 2798 & 1635 & $-285.8^{* * *}$ & -4.75 \\
\hline
\end{tabular}

Source: Own calculations based on SOEP data.

Notes: Low socio-economic status: isei score below 43 (out of 90). 
Figure B2: Probability of observing a local high-quality school by population size categories

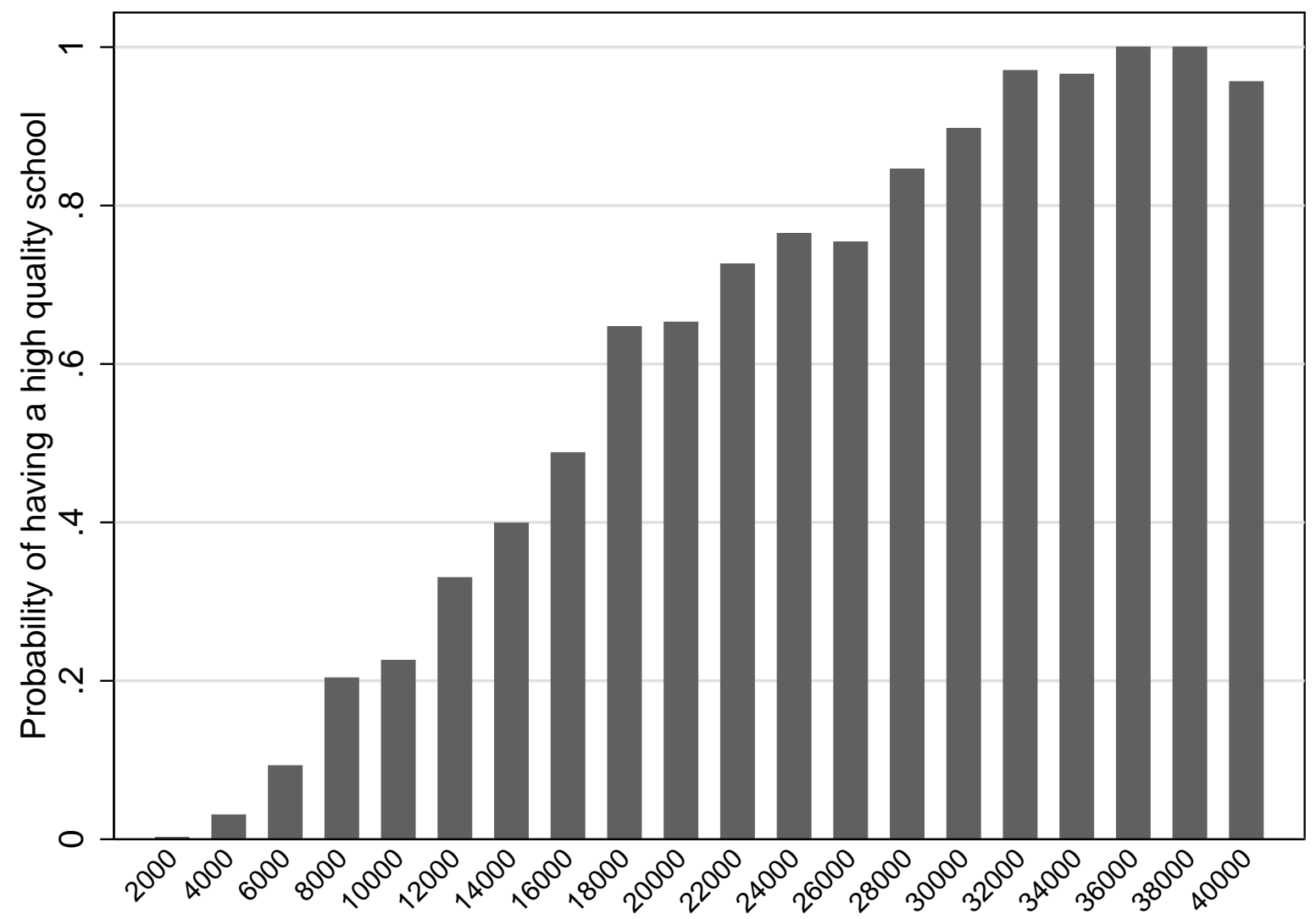

Notes: This figure shows the probability of observing a local high-quality school by the distribution of municipal population size. We grouped the data in bins of 2000 inhabitants (the labelling in the graphs shows the upper limit of each bin). On the y-axis we then plot the probability within each bin that town of that size have local high-quality school available. The data are taken from the year 1997. For this graph, we exclude municipalities larger than 40,000 inhabitants as there is no variation above that threshold. Source: Own calculation based on data from "Statistik Regional" and own collection. 
Figure B3: Location of high-quality schools in Bavaria (1997)

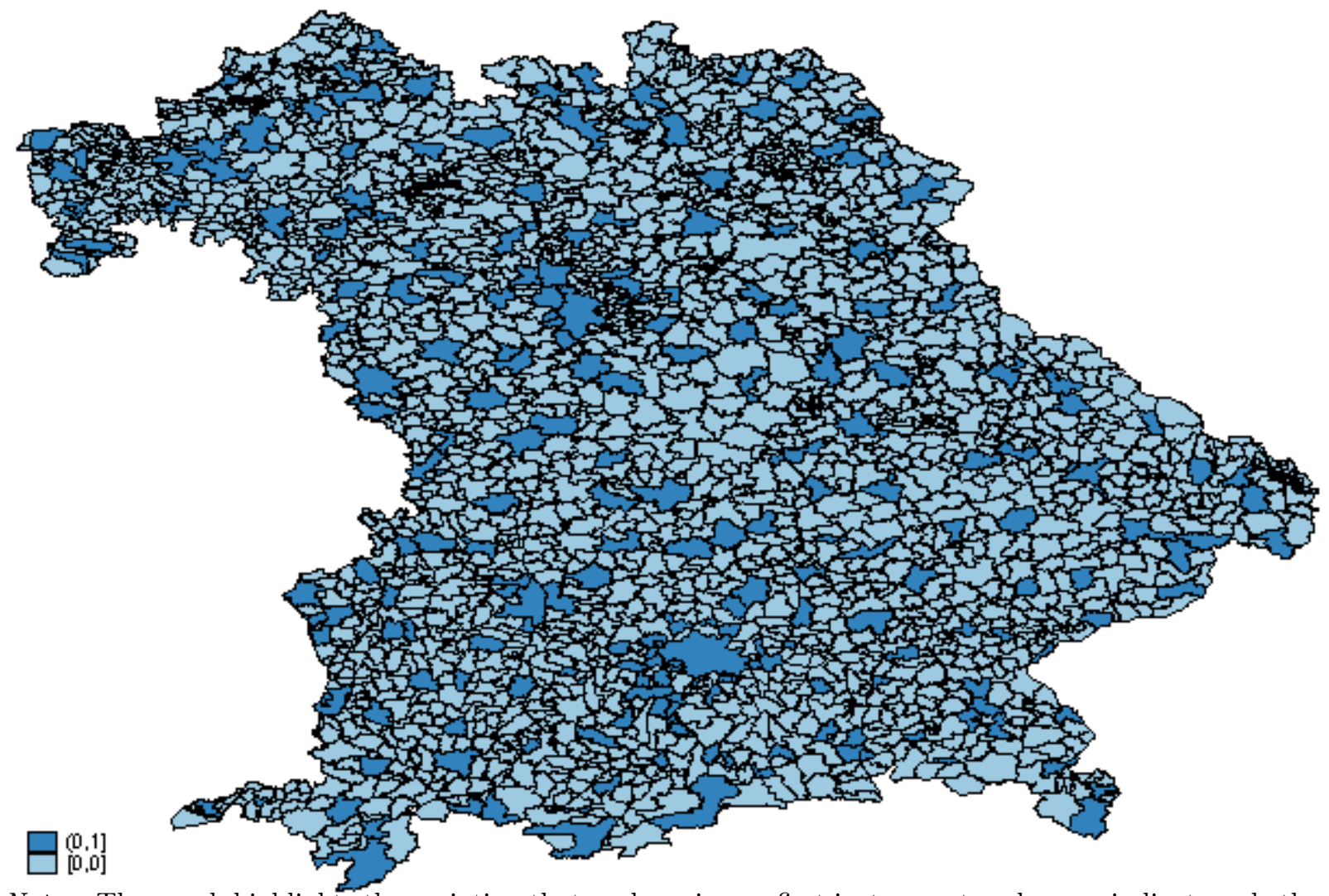

Notes: The graph highlights the variation that we have in our first instrument, a dummy indicator whether a town has a high-quality school locally available. For clarity, we only show municipalities from the state of Bavaria in the year 1997. The towns in the darker scale have a Gymnasium within town borders. Source: Own calculations based on data from "Statistik Regional" and own collection. 
Figure B4: Share of high-quality school attendees (by county in 1997)

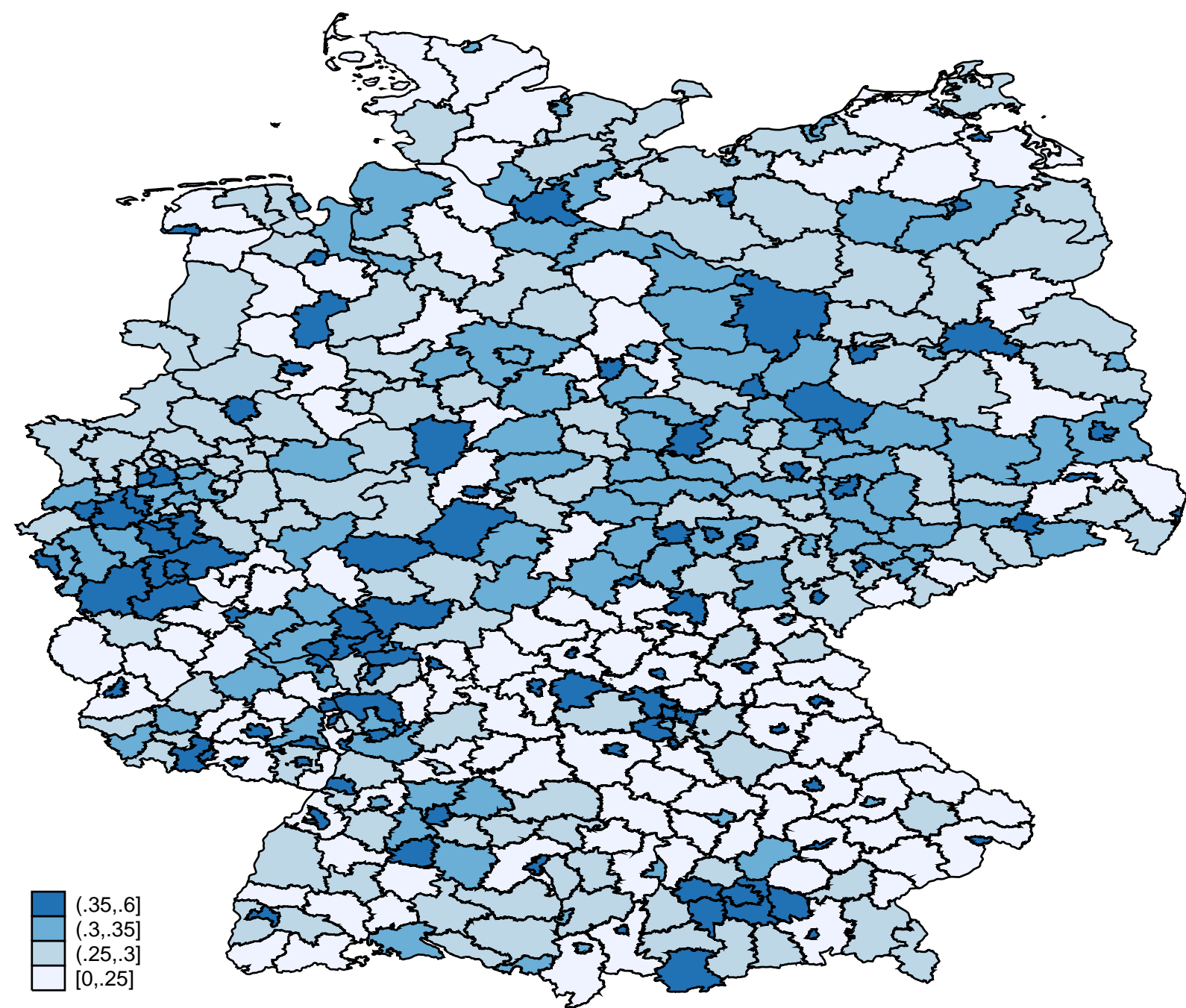

Notes: This graph shows the variation in our second instrument. Here, we use difference in the share of pupils (in all pupils) that can obtain a high-quality school placement in a specific county. In the graph, we highlight all 436 counties as of 1997. We separated the data roughly in four quartils going from white (0-25 percent of the pupils), to dimlight blue (25-30 percent), to light blue (30-35 percent) to dark blue (35 or more percent). Source: Own calculations based on data from "Statistik Regional" and own collection.s 
Table A4: Robustness: Different specifications of the Regression-control estimation

\begin{tabular}{lccccc}
\hline \hline & \multicolumn{5}{c}{ Dependent variable: Intention to } \\
\cline { 2 - 6 } & Probit & OLS & OLS & OLS & OLS \\
\hline \multirow{2}{*}{ finish the Abitur } & $(1)$ & $(2)$ & $(3)$ & $(4)$ & $(5)$ \\
\hline \multirow{2}{*}{ start college } & $0.351^{* * *}$ & $0.283^{* * *}$ & $0.280^{* * *}$ & $0.257^{* * *}$ & $0.266^{* * *}$ \\
& $(0.026)$ & $(0.025)$ & $(0.024)$ & $(0.029)$ & $(0.028)$ \\
& $0.247^{* * *}$ & $0.228^{* * *}$ & $0.219^{* * *}$ & $0.209^{* * *}$ & $0.212^{* * *}$ \\
Personal characteristics & $(0.029)$ & $(0.028)$ & $(0.027)$ & $(0.033)$ & $(0.032)$ \\
Set of state dummies & Yes & Yes & Yes & Yes & Yes \\
Set of cohort dummies & Yes & Yes & Yes & Yes & Yes \\
Set of community controls & Yes & Yes & Yes & Yes & Yes \\
Population controls & No & Yes & No & No & Yes \\
\hline N & 2679 & 2535 & 2670 & 2004 & No \\
\hline
\end{tabular}

Source: Own calculations based on SOEP data.

Notes: $(* * * / * * / *)$ : indicates significance at the $1 \%-/ 5 \%^{-} / 10 \%$-level. Robust standard errors in parentheses. Column 1: Marginal effect of high-quality school attendance on the outcome variables calculated from a probit-model. Column 2: Result from an OLS regression with population size of the community as an additional control. Column 3: Result from an OLS regression with county fixed effects. Column 4: Result from an OLS regression for only the western part of Germany. Column 5: Result from an OLS regression weighted with SOEP sampling weights. 